\title{
The Alaiz experiment: untangling multi-scale stratified flows over complex terrain
}

\author{
Pedro Santos $^{1}$, Jakob Mann ${ }^{1}$, Nikola Vasiljević ${ }^{1}$, Elena Cantero ${ }^{2}$, Javier Sanz Rodrigo ${ }^{2}$, \\ Fernando Borbón ${ }^{2}$, Daniel Martínez-Villagrasa ${ }^{3}$, Belén Martî ${ }^{3}$, and Joan Cuxart ${ }^{3}$ \\ ${ }^{1}$ DTU Wind Energy, Technical University of Denmark, Ris $\varnothing$ Campus, Roskilde, Denmark \\ ${ }^{2}$ National Renewable Energy Centre (CENER), Sarriguren, Spain \\ ${ }^{3}$ Physics Department, University of the Balearic Islands (UIB), Mallorca, Spain \\ Correspondence: Pedro Santos (paas@dtu.dk) and Jakob Mann (jmsq@dtu.dk)
}

Received: 15 June 2020 - Discussion started: 20 July 2020

Revised: 2 November 2020 - Accepted: 16 November 2020 - Published: 23 December 2020

\begin{abstract}
We present novel measurements from a field campaign that aims to characterize multi-scale flow patterns, ranging from 0.1 to $10 \mathrm{~km}$ in a time-resolved manner, in a mountainous region in northwestern Spain with a mountain-valley-ridge configuration. We select two flow cases where topographic-flow interactions were measured by five synchronized scanning Doppler wind lidars along a $10 \mathrm{~km}$ transect line that includes a cross section of the valley. We observed a hydraulic jump in the lee side of the mountain. For this case, the Froude number transition from supercritical $(>1)$ at the mountain to subcritical $(<1)$ at the valley is in agreement with previous experiments at a smaller scale. For a 1-year period, the measurements show such a transition about $10 \%$ of the time, indicating a possible high occurrence of hydraulic jumps. The second flow case presents valley winds that are decoupled from the northerly flow aloft and show a stratified layered pattern, which is well captured by the lidar scans and complementary ground-based observations. These measurements can aid the evaluation of multi-scale numerical models as well as improve our knowledge with regards to mountain meteorology.
\end{abstract}

\section{Introduction}

Over flat and homogeneous terrain, such as areas far offshore, the difference between measured and simulated climatological mean wind speeds at wind-energy-relevant heights is in some cases less than $4 \%$ (Olsen et al., 2017). This is historically low although there is still economic value in reducing it even further. However, over complex terrain, with steep slopes and varying land cover, such differences can be closer to $10 \%$ (Dörenkämper et al., 2020) depending on terrain complexity, implying large uncertainties on the estimated annual energy production of wind farms. Even small deviations in the terrain description over a given area may result in substantial differences in the simulated flow (Lange et al., 2017).

For the prediction of winds in complex terrain, mesoscale models, typically covering scales down to a kilometer or so, have to be coupled with microscale models that cover smaller scales down to meters. Meso- and microscale models are fun- damentally different in the sense that flow processes that are parameterized in the former are resolved in the latter, while several physical processes, e.g., cumulus clouds and convective systems, are included in the former but not in the latter. The scales that are at the interface of the two models have been dubbed terra incognita by Wyngaard (2004), and this experimental investigation aims to explore some submesoscale physical processes. New datasets from complex terrain experiments with details on flow patterns covering these scales are scarce and needed to evaluate and quantify the uncertainty of numerical models (Mann et al., 2017; Sanz Rodrigo et al., 2017). Apart from wind energy, untangling flow over complex terrain is of general interest for the mountain meteorology community (Serafin et al., 2018).

Over the last decades, experimental efforts have been conducted with increasing density of instruments and types of measurement aiming to better understand flow conditions in hilly and mountainous terrain. A well-known experiment was 
performed at the Askervein Hill, which became the main reference in the development and validation of pioneering analytical and linearized flow models dealing with gently sloping terrain (Salmon et al., 1988; Walmsley and Taylor, 1996). Furthermore, the Cooper's Hill experiment (Coppin et al., 1994) used meteorological masts and sonic anemometers to study the flow over a ridge as a function of atmospheric stability.

In more recent endeavors, Doppler wind lidars and airborne instrumentation have been used to characterize largescale phenomena over steep hills and mountain ranges. Two examples of such are the terrain-induced rotor experiment (T-REX, Grubišić et al., 2008) and the mountain terrain atmospheric modeling and observations program (MATERHORN, Fernando et al., 2015). T-REX focused on lowlevel vortices formed downstream of a mountain ridge, and MATERHORN was a multidisciplinary initiative to approach large-scale atmospheric phenomena in complex terrain, where two major experimental campaigns studied thermally driven winds with strong synoptic forcing. Back to smaller scales, detailed scanning lidar and turbulence measurements were performed at the escarpment of Bolund (Lange et al., 2016; Berg et al., 2011), which detailed turbulence characteristics under flow-terrain interaction. A blind test followed to compare a wide variety of flow models (Bechmann et al., 2011) and wind tunnel prototypes (Kilpatrick et al., 2016; Conan et al., 2016; Lange et al., 2017).

With an extensive collaboration effort in the pursuit of new insights on wind resource characterization, a range of experiments, both onshore and offshore, were performed within the New European Wind Atlas (NEWA) project to evaluate meso- and microscale models (Mann et al., 2017). The experiments made extensive use of a recently developed infrastructure that uses synchronized measurements from multiple lidars, the so-called long-range WindScanner system (Vasiljević et al., 2016). The Kassel experiment, performed at the forested hill Rödeser Berg in Germany, was used to quantify the accuracy in the reconstruction of the wind vector with distinct multi-lidar combinations and the lidar's spatial averaging effect on the turbulence spectra (Pauscher et al., 2016). A methodology for the execution of experiments involving multi-lidars was developed during the double-ridge Perdigão experiment in Portugal (Vasiljević et al., 2017), which is the largest experimental venture in complex terrain to date in terms of density of measurement equipment (Fernando et al., 2019). In parallel to the NEWA project, the second Wind Forecast Improvement Project (WFIP2) also deployed a large array of instruments to cover the area around the Columbia River Gorge in the United States (Wilczak et al., 2019). This experiment was also focused on the improvement of mesoand microscale coupling methods (Haupt et al., 2019).

The Inn Valley, located close to Innsbruck, Austria, is a site where extensive field campaigns took place to characterize atmospheric processes with regards to mountain meteorology. Recent experiments used multiple wind lidars to

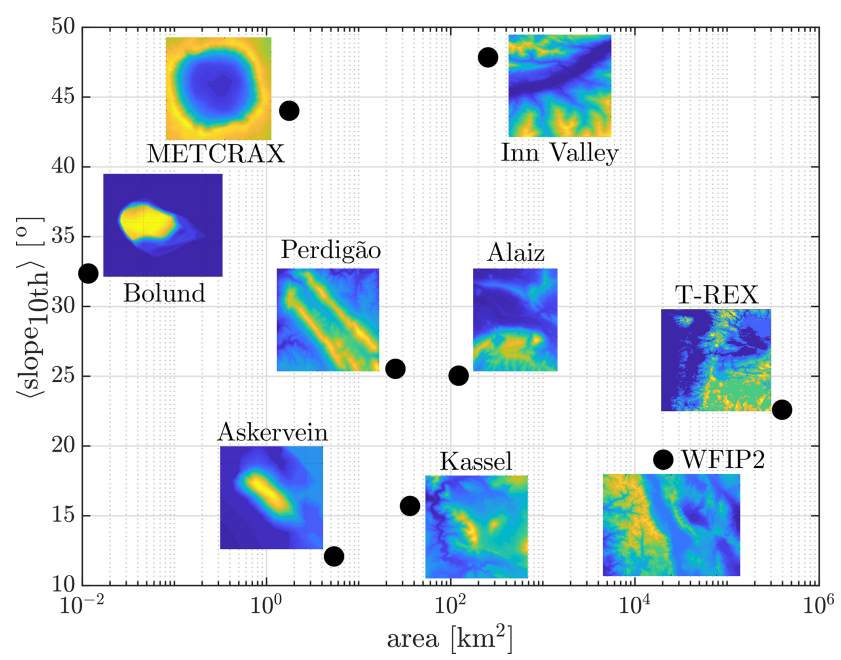

Figure 1. Illustration of the complexity of some atmospheric flow experiments as a function of their area of coverage. The complexity is in terms of the slope: the average 10th percentile of the highest slopes. The inserts besides the markers show contour maps of the relative elevation for each site, where blue and yellow colors represent low and high elevations, respectively.

obtain flow patterns to characterize cold-air pool erosion by downslope mountain winds (Haid et al., 2020) as well as cross-valley circulation cells using coplanar multi-lidar observations (Adler et al., 2020).

Figure 1 puts the Alaiz experiment in perspective of these complex terrain experiments by comparing the area covered and steepness of the terrain quantified by the upper 10th percentile of the slopes. The color in the inserts covers the elevation range of each site. In this context, Askervein can be seen as a departure point that gave rise to experiments in larger areas and steeper slopes.

With a small domain but a steep escarpment, Bolund left the realm of gentle slopes and hence emphasized the limitations of linearized flow models and eventual biases of nonlinear simulations. Due to the very small scales, neglecting the effects of atmospheric stability did not lead to major variations in the flow pattern over Bolund (Berg et al., 2011). On the other hand, in METCRAX II, scanning lidars captured atmospheric hydraulic jumps and cool pool events inside a meteorite crater in Arizona (Lehner et al., 2016). In Kassel and Perdigão, larger areas were investigated that required the use of long-range scanning lidars. Perdigão presents a double-hill configuration, $1.5 \mathrm{~km}$ apart, which is dominated by microscale effects, such as valley winds and recirculation zones, but is also affected by thermal stratification effects that can lead to internal atmospheric gravity waves under stable conditions (Menke et al., 2019; Palma et al., 2019). T-REX and WFIP2 are mountain range studies that are too large to be fully covered by a single set of instruments but still have similar thermally stratified flows presented in this study. In the extreme of terrain complexity, the Inn Valley area hosted 

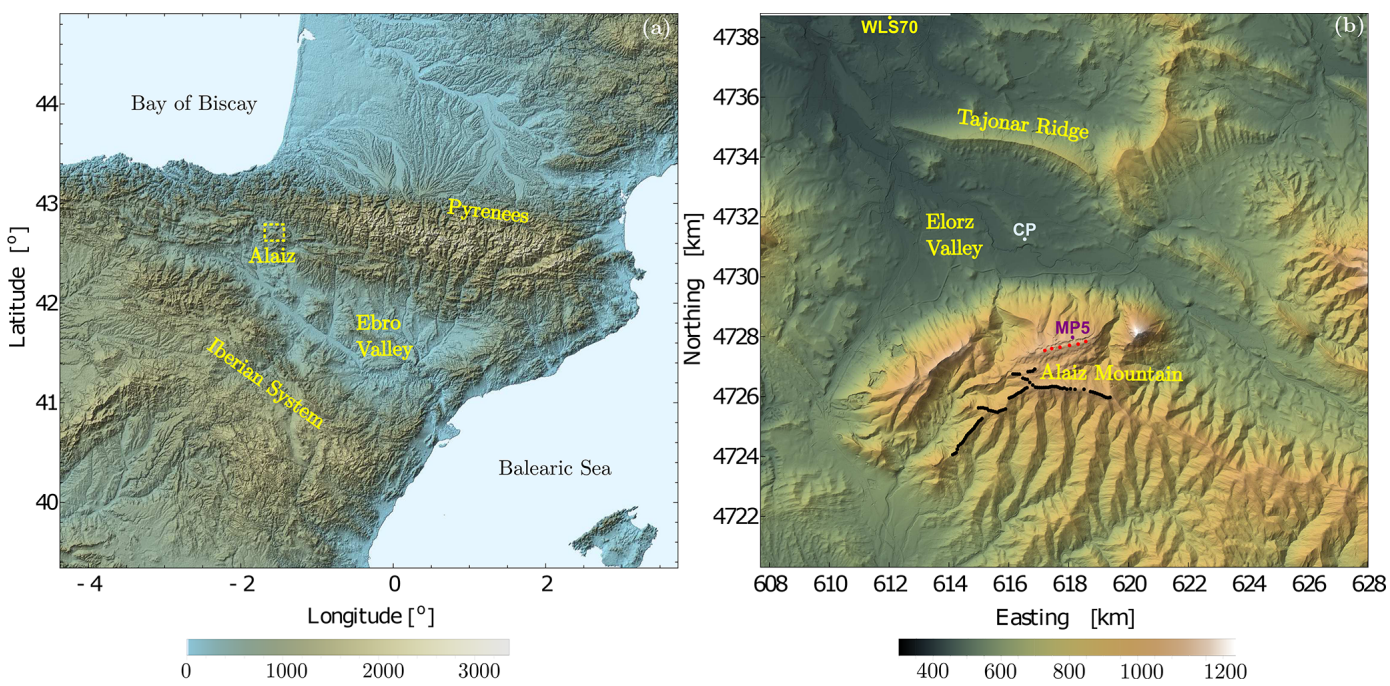

Figure 2. Location and overview of ALEX17. Panel (a) shows the experiment location (yellow rectangle) within the Iberian Peninsula. The experiment is shown in panel (b), with CENER's wind turbine test stands (red) and reference MP5 meteorological mast (purple), Acciona's wind farms (black), and the central position (CP, light blue) and a profiling wind lidar (WLS70, yellow). The color bars represent the height above mean sea level in meters based on digital elevation models from SRTM (a) and lidar aerial scans (b) in UTM30 WGS84.

multiple experimental campaigns to cover such an alpine region.

As highlighted by Mann et al. (2017), Alaiz covers the mid-range where both microscale and mesoscale effects are prevalent. As shown in Fig. 1, Alaiz features similar complexity as Perdigão but is an order of magnitude larger with influence of topographic features that are $10 \mathrm{~km}$ or more apart. The area to cover is still within the range of current commercial wind lidars.

This paper firstly introduces the Alaiz experiment (ALEX17), which aims to peer into multi-scale flow patterns with mountain-valley interactions. Secondly, in this work, we are describing two types of flow cases: a layered stratified valley flow and a hydraulic jump, characterized with multilidar measurements and multiple ground-based observations.

This paper is outlined as follows. In Sect. 2 we describe the experimental layout and detail the measurement equipment. Section 3 describes the site climatology, and the atmospheric stability is assessed. In Sect. 4 we characterize and discuss the two selected flow cases. Section 5 summarizes the main findings and promotes this data collection as a tool for further analysis and numerical model evaluation.

\section{The ALEX17 experiment}

\subsection{Site characterization}

ALEX17 took place in the Navarre region, in the northern part of Spain. The experimental area encompasses the Alaiz mountain range, a region at $1000 \mathrm{~m}$ a.m.s.l. (above mean sea level) with a wind regime favorable for wind energy applications (Sanz Rodrigo et al., 2013). Figure 2a shows the ex- perimental domain (yellow square) within the Iberian Peninsula with a 1 arcsec resolution elevation map from the Shuttle Radar Topographic Mission (SRTM). The site is situated to the northwest of the Ebro valley, a river basin enclosed by the Pyrenees to the north and the Iberian system to the south.

The large-scale topographical features in the region explain the synoptic forcing present on this site. Jiménez et al. (2013) performed mesoscale modeling with $2 \mathrm{~km}$ horizontal resolution over 45 years and assessed the wind variability over the region. Badger et al. (2014) presented a statisticaldynamical downscaling to estimate a generalized wind climate in the same area. Apart from inherent biases between model and observations, both studies showed two main circulation patterns, with northwest (NW) and southeast (SE) flow over the Ebro valley, with a channeling effect caused by an orographic funnel formed by the large-scale features (see Fig. 2a). The NW circulation is ordinarily called "cierzo". Badger et al. (2014) additionally showed that this effect is intensified during stable conditions, where the stratified atmospheric boundary layer (ABL) interacts with the orography more actively.

Figure $2 \mathrm{~b}$ shows the area surrounding the experimental domain with a $2 \mathrm{~m} \times 2 \mathrm{~m}$ resolution terrain elevation map based on airborne lidar scans (Chavez Arroyo, 2019). The Alaiz mountain, to the south, hosts CENER's wind turbine test site in complex terrain with six test stands (red dots) and a $118 \mathrm{~m}$ meteorological mast called MP5 (purple dot). The other test site's masts (not shown) are not part of this experiment. To the south of the mountain plateau, 89 wind turbines (black dots) belong to Acciona's wind farms called Alaiz and Echagüe, which shows that the site, although challenging, is attractive for wind energy production. 


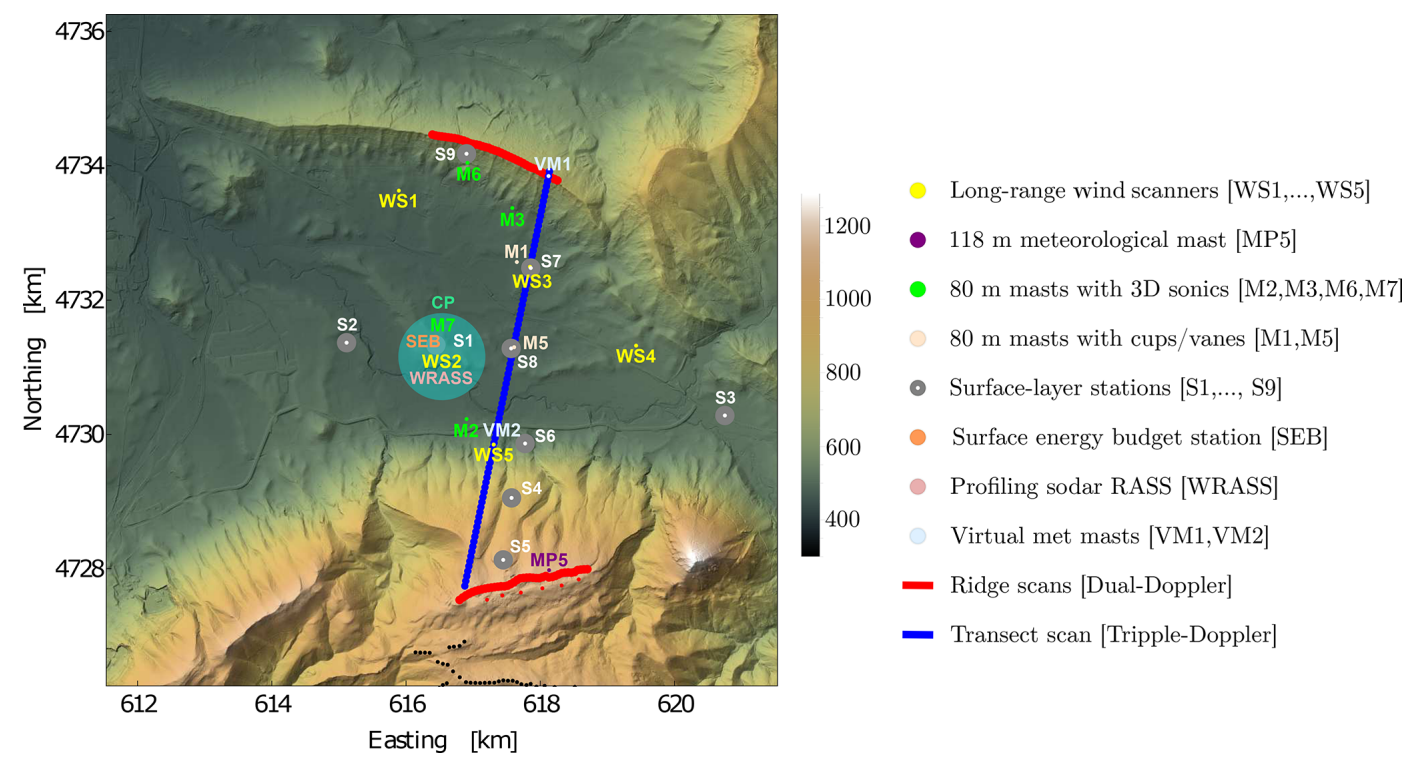

Figure 3. Instrumentation layout of the ALEX17 campaign within the $10 \mathrm{~km} \times 10 \mathrm{~km}$ experimental domain centered at CP. The legend details each type of measurement station. The transect scan (blue line), detailed in Fig. 4, is the focus of this study.

To the north of the Alaiz mountain range, most of the measurement equipment is located at the Elorz valley, 500 ma.s.l., around the central position (CP, blue dot) of the experimental domain. The valley is roughly $10 \mathrm{~km}$ wide and $6 \mathrm{~km}$ long, bounded by the Tajonar ridge, hereafter called north ridge, which has its peak at $850 \mathrm{ma}$ a.s.l. Notice that, as in the large-scale features, the Alaiz mountain and the north ridge are not parallel, also shaping the valley as a funnel. The land cover is heterogeneous (cf. Fig. 4 in Cantero et al., 2019), with villages and distinct kinds of farmland distributed along the valley floor, as well as forest patches on the slopes of the north ridge and the top of Alaiz mountain.

\subsection{Timeline and instrumentation}

The extensive measurement period (EMP) ran from July 2017 to July 2019, comprising 2 full years of measurements from the reference mast MP5 and from a long-range profiling wind lidar (WLS70, Leosphere Inc., Saclay, France) located at the north boundary of the domain (see Fig. 2b). The Intensive Observational Period (IOP), when all sensors had concurrent measurements, lasted for 5 months from August 2018 to December 2018.

Figure 3 shows the $100 \mathrm{~km}^{2}$ experimental domain, with $\mathrm{CP}$ at the center and details of the instrumentation layout. Most instruments were placed in the valley floor, aiming to investigate the topographic interaction on the flow between Alaiz mountain and the north ridge in order to characterize the wind regime at the mountaintop, regarded as the region of interest for wind energy. Cantero et al. (2019) documented the ALEX17 campaign, with detailed technical specifications of each of the instruments, together with their geographi- cal coordinates, as well as their operating periods and data availability. Here, we summarize the instruments used in this study.

\subsubsection{Reference meteorological mast (MP5)}

This is a $118 \mathrm{~m}$ meteorological mast located at the mountaintop $\left(42^{\circ} 41.7^{\prime} \mathrm{N}, 1^{\circ} 33.5^{\prime} \mathrm{W}\right)$. We selected this mast as a reference because it has been measuring continuously since 2011 with the same configuration. The wind speed and wind direction data availability at $118 \mathrm{~m}$ was $85.4 \%$ between February 2011-January 2019 . The mast is equipped with wind and temperature measurements distributed in six main levels: 2 , 40, 80, 90, 100 and $118 \mathrm{ma.g.l}$. (above the ground level).

\subsubsection{Long-range WindScanner units}

Five WindScanner units were distributed along the valley floor, depicted with yellow markers in Fig. 3. By scanning on vertical planes across the valley, it is possible to visualize the dynamics of multi-scale flow patterns generated by the interaction between the ABL and the topography such as atmospheric waves or flow-separation regions in the lee side of the ridges. We configured the units to synchronously scan in pairs and triplets, allowing the wind vector reconstruction on top of the ridges and across the valley, shown by red and blue lines in Fig. 3 and detailed in Sect. 2.3.

\subsubsection{Meteorological masts (M)}

Six $80 \mathrm{~m}$ tall meteorological masts were distributed across the valley, marked with distinct colors in Fig. 3 for masts with either cup/vanes or 3-D sonic anemometers. They are 
Table 1. Half-hourly repeating schedule of scanning strategies.

\begin{tabular}{|c|c|c|c|}
\hline WindScanner & First 10 min interval & Second $10 \mathrm{~min}$ interval & Third 10 min interval \\
\hline WS1 & North ridge scan $^{\mathrm{a}}$ & Virtual mast (VM1) ${ }^{b}$ & North ridge scan ${ }^{\mathrm{a}}$ \\
\hline WS2 & Virtual mast (VM2) ${ }^{\mathrm{a}}$ & Transect scan ${ }^{\mathrm{a}}$ & South ridge scan $^{\mathrm{a}}$ \\
\hline WS3 & North ridge $\operatorname{scan}^{\mathrm{a}}$ & 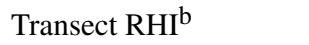 & North ridge scan $^{\mathrm{a}}$ \\
\hline WS4 & Virtual mast $(\mathrm{VM} 2)^{\mathrm{b}}$ & Transect scan ${ }^{\mathrm{a}}$ & South ridge scan ${ }^{\mathrm{a}}$ \\
\hline WS5 & Virtual mast (VM2) ${ }^{\mathrm{b}}$ & Transect RHI + VM1 $1^{b}$ & Transect RHI ${ }^{\mathrm{b}}$ \\
\hline
\end{tabular}

Scans with ${ }^{\mathrm{a}}$ are fully synchronized and those with ${ }^{\mathrm{b}}$ start simultaneously at every interval.

located either on the valley floor or in the north ridge slopes. They provide wind speed, wind direction, temperature, and turbulent momentum and sensible heat fluxes (for the ones with sonic anemometers) profiles at five main levels: 10, 20, 40, 60 and $80 \mathrm{~m}$. In this study, we use Gill WindMaster Pro sonic anemometers and air temperature measurements from M3, M7 and M2, located at the north ridge slope, CP and Alaiz foothills, respectively.

\subsubsection{Surface-layer stations (S)}

Due to the heterogeneous land cover, estimation of the horizontal distribution of surface fluxes along the valley and mountain slopes became a need. Nine surface-layer stations, shown with gray markers in Fig. 3, were deployed for this. Each station had a 2-D sonic anemometer at $2 \mathrm{ma}$ a.g.l., two levels of temperature ( 0.36 and $2 \mathrm{ma.g} .1$.), and soil heat flux measurements at a depth of $0.08 \mathrm{~m}$ along with soil moisture and temperature at a depth of $0.05 \mathrm{~m}$. These stations were used in a previous study to successfully characterize the spatial variability of atmospheric and soil patterns close to the surface at the hectometer scale (Simó et al., 2019).

\subsubsection{Central position (CP)}

This is considered a major location of the experiment due to its density of instruments (see Fig. 3). The CP is located in the middle of the valley, with relatively flat surroundings and farmland as the predominant land cover. Apart from WS2 and M7, there was (i) a radar acoustic sounding system, windRASS (Scintec AG, Rottenburg, Germany), capable of measuring wind and virtual temperature profiles up to 400 ma.g.l.; and (ii) a surface energy budget (SEB) station, able to estimate the four main components of the surface energy balance (i.e., net radiation, sensible and latent heat fluxes, and ground heat flux). Previous studies in the Ebro valley used the SEB to quantify significant imbalances in the energy budget (Cuxart et al., 2015) and observed the occurrence of low-level jets and katabatic winds with windRASS (Cuxart et al., 2012).

\subsection{WindScanner measurements}

The planning of ALEX17 WindScanner scanning strategies was built upon the experience of previous experiments (Pauscher et al., 2016; Vasiljević et al., 2017; Menke et al., 2019). ALEX17 used a combination of five long-range wind scanners (LRWSs), which can be collocated with a pointing accuracy of up to $0.05^{\circ}$ and synchronized in time within $10 \mathrm{~ms}$ (Vasiljević et al., 2016). The campaign lasted for almost 9 months from May 2018 to January 2019. The pointing error during the IOP was kept within $0.2^{\circ}$ based on regular hard target mapping (cf. Table 4 in Cantero et al., 2019), which represents a deviation of $14 \mathrm{~m}$ at a line-of-sight distance of $4000 \mathrm{~m}$.

To execute the ridge, transect and virtual meteorological masts scans shown in Fig. 3, a total of seven scanning strategies were designed and programmed. With more planned scans than available lidars, each system was scheduled to perform a cycle of three scanning strategies, each lasting $10 \mathrm{~min}$; i.e., all trajectories are completed at least twice per hour (four times for the north ridge scan). Table 1 shows the final schedule for each lidar system.

The ridge scans, shown as red lines in Fig. 3, were each composed of 40 evenly distributed points $50 \mathrm{~m}$ apart, which followed the terrain profile at $125 \mathrm{ma}$.g.l. Table 1 shows which pairs of LRWSs were programmed to measure synchronously by traversing the beams through the ridgeline points $\left({ }^{\mathrm{a}}\right)$, i.e., dual-Doppler measurements. The virtual meteorological masts were defined by the intersection of range-height indicator (RHI) scans. VM1 extended up to 1400 ma.g.l. and was measured with WS1 and WS5 during the second interval, whereas VM2 went up to 1200 ma.g.l. and consisted of three RHI scans performed by WS2, WS4 and WS5 (triple-Doppler). The RHIs were coordinated, i.e., not fully synchronized $\left({ }^{b}\right)$, with the laser beams not visiting the same points of the virtual mast at the exact same time.

Figure 4 shows a cross section of the transect scan, defined by the vertical plane spanned by WS3 and WS5. The transect scan (blue dots) followed the terrain profile (gray area) at $125 \mathrm{ma}$ a.g.l. The scan is measured synchronously by WS2 and WS4 at 85 equally spaced points $50 \mathrm{~m}$ apart, starting at the north ridge (location of VM1, light blue markers) and ending at the top of the Alaiz mountain, where it met the 


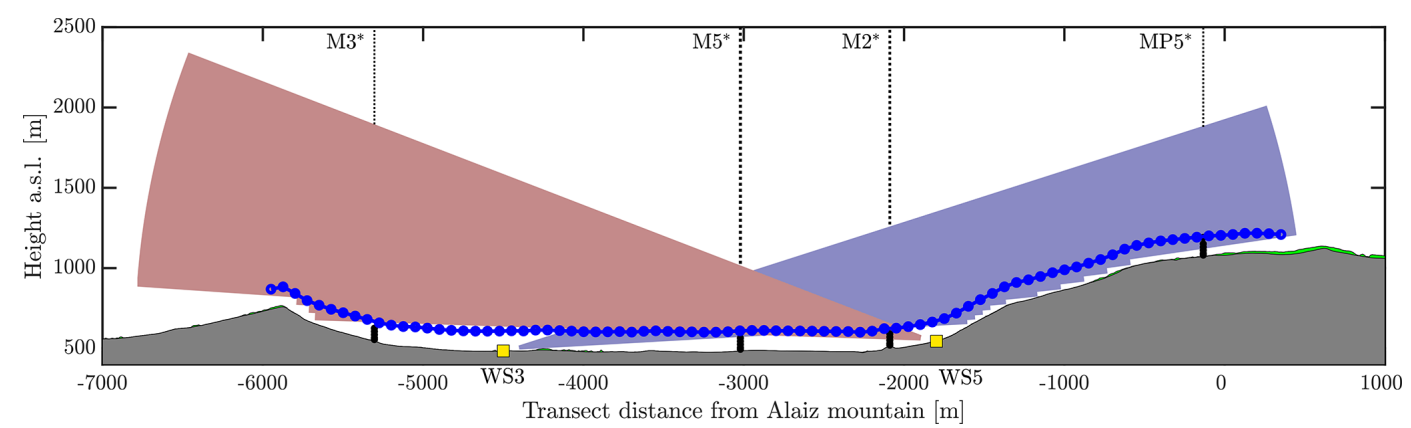

Figure 4. Transect scan on the vertical plane spanned by WS3 and WS5 (yellow squares). Shaded areas represent the superimposed RHI scans after a hard target filtering. The blue dots show the transect scan measured by WS2 and WS4 (out of the plane). The black dots indicate the positions of the masts M3, M5, M2 and MP5 when projected onto the transect's plane.

westernmost point of the south ridge scan. Two overlapping RHIs with opening angles of 15 and $20^{\circ}$, respectively, extend the scan curve upward. See table A1 for further details of these RHI scans.

All RHIs had a range of $5 \mathrm{~km}$, but valid measurements are dependent on data filtering criteria that disregard regions, e.g., with low clouds and fog, especially near the Alaiz mountain ridge. Measurements from some meteorological masts are here used to explain flow patterns measured by the RHIs. Hence, the positions of M3, M5, M2 and MP5 were projected onto the transect plane as reference (black dots).

Each RHI scan in Fig. 4 took $\approx 30 \mathrm{~s}$, so we ensembleaverage 20 scans per 10 min period, computed twice every hour. Before averaging a scan, two noise filters are applied: (i) a hard target filter, which finds range gates with carrier-tonoise ratio (CNR) larger than or equal to $5 \mathrm{~dB}$ and removes all range gates beyond this point (see Fig. 4); and (ii) the variation of the radial velocity $v_{\mathrm{r}}$ between consecutive range gates along each line of sight, which is estimated to filter out values larger than $1.5 \mathrm{~m} \mathrm{~s}^{-1}$.

These multi-lidar scanning patterns provided 2-D and 3-D wind reconstruction over the ridge scans (red lines) and transect scan (blue line), respectively. The combined Z-shaped transect (Fig. 3) had a length of $10 \mathrm{~km}$ and is a unique feature of this experiment. Additionally, after the IOP all systems performed a 1-month campaign aiming at M7's $80 \mathrm{~m} 3$ $\mathrm{D}$ sonic and storing, in addition to the wind speeds, the raw Doppler spectra. The Z-shaped transect's UTM coordinates can be found in the Supplement.

\section{Site wind conditions}

\subsection{Site climatology}

The reference meteorological mast MP5 has 8 years of continuous wind speed and wind direction measurements from a calibrated cup anemometer and wind vane at $118 \mathrm{ma}$ a.g.l. Figure 5a shows the wind climatology with a wind rose from the period between February 2011 to January 2019. The
Alaiz mountaintop presents a mean wind speed of $8.6 \mathrm{~m} \mathrm{~s}^{-1}$ at $118 \mathrm{~m}$ with a turbulence intensity of $7 \%$ at $15 \mathrm{~ms}^{-1}$ as well as a bidirectional regime, with prevailing winds from a north-northwest sector $\left(330-360^{\circ}, 32 \%\right.$ of total) and a southsoutheast sector $\left(150-180^{\circ}, 23 \%\right.$ of total).

Figure 5b shows the wind rose of ALEX17's 2-year extensive measurement period, from July 2017 to July 2019, which has a representative wind regime when compared with the long-term climatology. As the MP5 is located next to the wind turbines during power curve measurements, it is susceptible to wind turbine wake effects with winds between 130 and $240^{\circ}$ (see Fig. 3).

In complex terrain, the characterization of spatial variability is critical to capture a full picture of the wind regime. Figure 6a illustrates this with the wind rose measured at the valley floor by M5 during the EMP. Comparing the mountaintop (Fig. 5) with the valley floor (Fig. 6a), we observe a turning effect with NW and SE valley winds. Higher wind speeds come from the SE, confirming the funnel effect caused by the valley conical section with a larger area facing west (see Fig. 2b). Furthermore, the turbulence intensity is higher at the valley floor when compared to the mountaintop, being $11 \%$ at $15 \mathrm{~m} \mathrm{~s}^{-1}$ at $80 \mathrm{~m}$ from M5 observations.

The combination of topographic features $\mathcal{O}(10 \mathrm{~km})$ away and elevation changes up to $700 \mathrm{~m}$ between the valley floor and mountaintop poses a challenge to numerical models such as the Weather Research and Forecast Model (WRF). The NEWA project delivered a wind atlas for all European countries using WRF with a horizontal and temporal resolution of $3 \mathrm{~km}$ and $30 \mathrm{~min}$, respectively (Hahmann et al., 2020; Dörenkämper et al., 2020). Here called NEWA-WRF, this model output is publicly available and covers a 30 -year period (1989-2018).

Figure $6 \mathrm{~b}$ compares the wind distribution measured at MP5 during both the long-term reference period (February 2011-January 2019) and the EMP (July 2017-July 2019) with the simulated distribution from NEWA-WRF also from the long-term period. The model output was extracted at the MP5 position using a linear interpolation of the nearest 


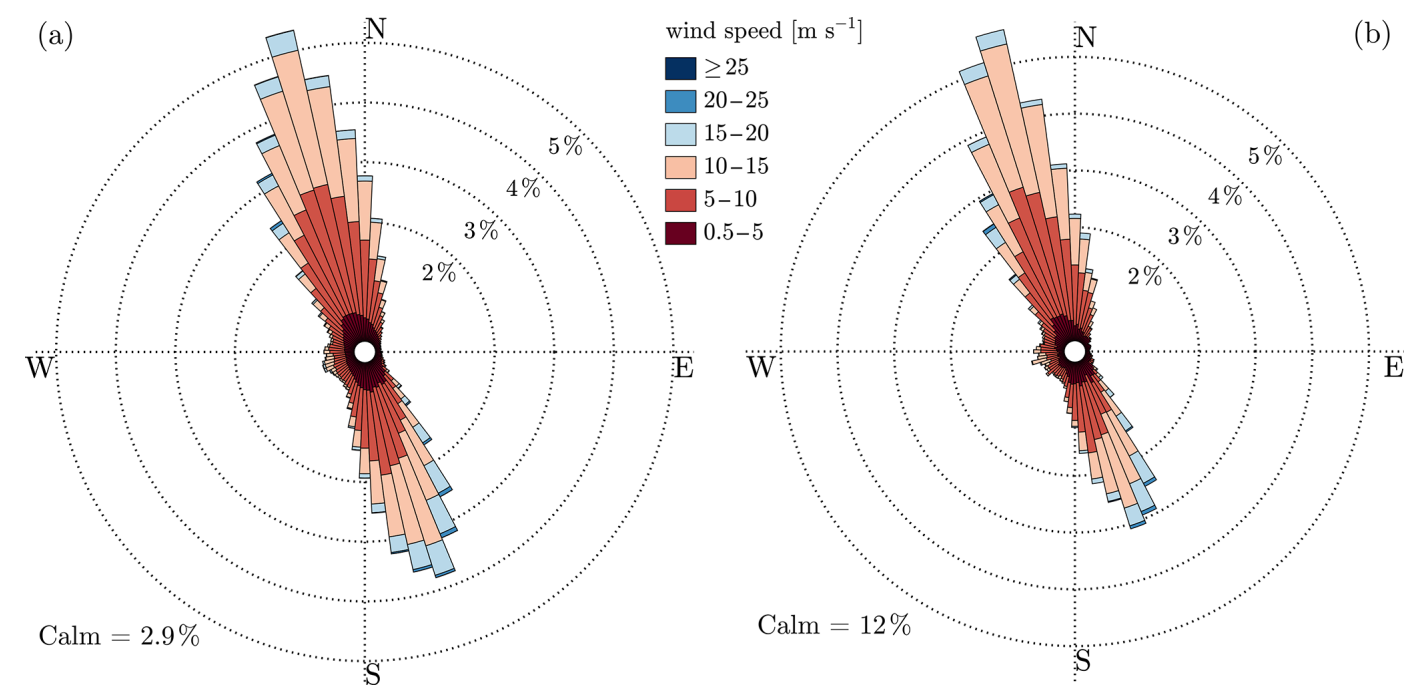

Figure 5. Wind roses of $10 \mathrm{~min}$ wind speeds observed by MP5 at $118 \mathrm{~m}$ for the reference period (2011-2019) (a) and during the EMP (b). The calm threshold is $0.5 \mathrm{~m} \mathrm{~s}^{-1}$. Each bin contains a $5^{\circ}$ wind direction interval and circular grid labels indicate the percentage of occurrence.
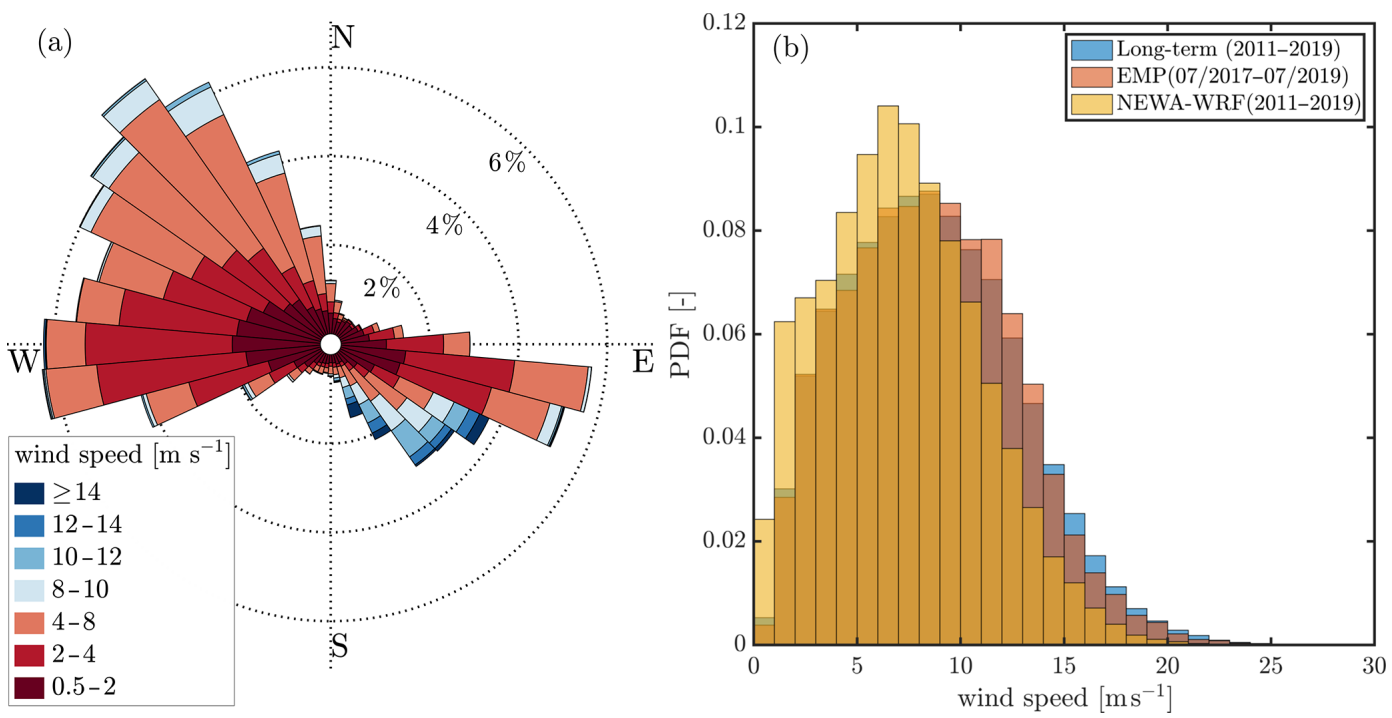

Figure 6. Panel (a) shows the wind rose of 10 min wind speeds at the valley measured by M5 at $80 \mathrm{ma}$.g.1. Panel (b) shows the wind speed distributions at $118 \mathrm{~m}$ a.g.l. measured at MP5 during the reference period and EMP along with the modeled wind speeds from NEWA-WRF for the reference period.

neighbor grid cells as well as the nearest vertical levels. Results show that the NEWA-WRF simulations underestimate the mean wind by more than $1.5 \mathrm{~m} \mathrm{~s}^{-1}$, which is indicative of unresolved speed-up effects in the mesoscale model. The measured wind distribution further confirms that the EMP contains a representative set of meteorological conditions.

An extensive study evaluated the mean wind speed bias between measurements and NEWA-WRF simulations using 291 onshore masts over Europe, where complex sites are defined as having $2 \%$ of their slopes higher than $16.7^{\circ}$ within a radius of $3.5 \mathrm{~km}$ (Dörenkämper et al., 2020). Results showed that the selected NEWA-WRF setup in complex sites has a mean wind speed bias of $-0.25 \pm 0.83 \mathrm{~m} \mathrm{~s}^{-1}$. Based on Fig. 6b, ALEX17 has a much larger systematic underestimation of the wind speed when compared to NEWA-WRF's validation study, as expected since at MP5 $20 \%$ of the slopes exceed $16.7^{\circ}$. In order to improve modeling here we need to further downscale NEWA-WRF using non-linear microscale models.

\subsection{Atmospheric stability}

Monin-Obukhov similarity theory (MOST) is commonly used to describe the mean and turbulence characteristics of 

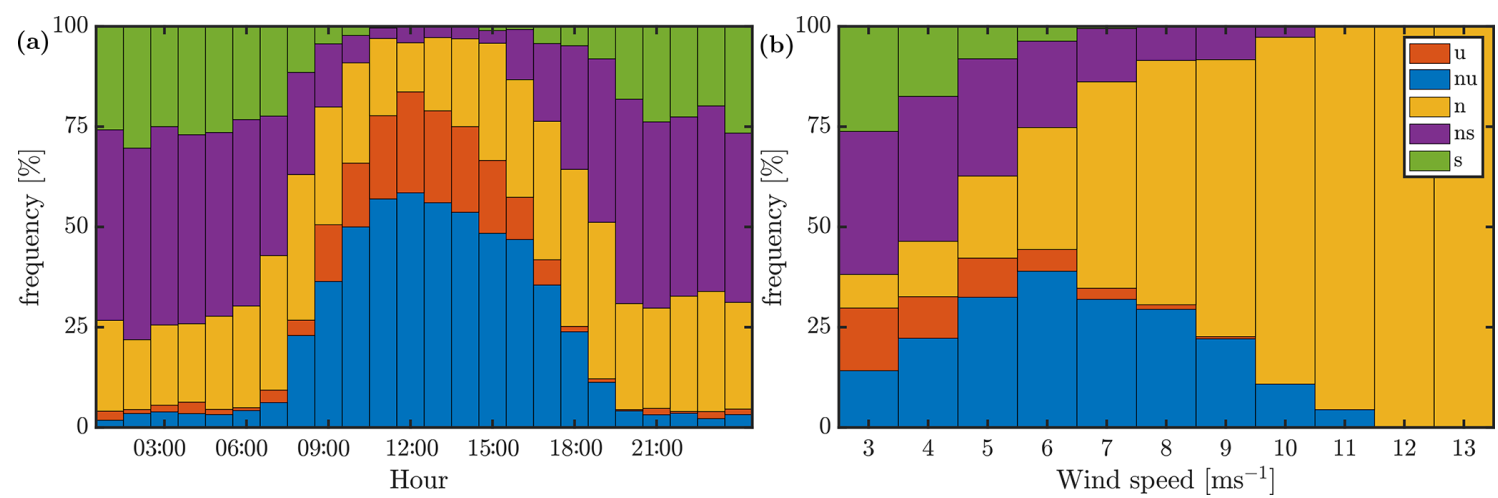

Figure 7. Frequency of $z / L$ at $10 \mathrm{ma.g} .1$. divided in stability classes per hour (a) and per wind speed (b) from measurements at M7. The stability classes are found in Table 2 . The time is in UTC.

Table 2. Definition of atmospheric stability classes within intervals of $z / L$ and respective quantity of $30 \mathrm{~min}$ profiles.

\begin{tabular}{llr}
\hline Stability class & $z / L$ & No. of 30 min profiles \\
\hline Unstable (u) & $z / L \leq-0.2$ & 572 \\
Near unstable (nu) & $-0.2<z / L<-0.04$ & 904 \\
Neutral (n) & $|z / L| \leq 0.04$ & 1447 \\
Near stable (ns) & $0.04<z / L<0.2$ & 1115 \\
Stable (s) & $z / L \geq 0.2$ & 1054 \\
\hline
\end{tabular}

the flow within the surface layer (Foken, 2006). MOST assumes that, over horizontally homogeneous and flat terrain (HHF) conditions, normalized atmospheric gradients such as those of wind and temperature are functions of the dimensionless parameter $z / L$, where $z$ is the height above ground and $L$ is the Obukhov length, which is defined here as $L=-\left(u_{*}^{3} T_{\mathrm{s}}\right) /\left(\kappa g \overline{w^{\prime} T_{\mathrm{s}}^{\prime}}\right)$, where $u_{*}=\left({\overline{u^{\prime} w^{\prime}}}^{2}+{\overline{v^{\prime} w^{\prime}}}^{2}\right)^{1 / 4}$ is the friction velocity, $\kappa=0.4$ the von Kármán constant, $g$ the acceleration due to gravity and $T_{\mathrm{S}}$ the sonic anemometer temperature. The prime $(')$ denotes fluctuations and the overbar a mean. The velocity components $u, v$ and $w$ refer to the stream-wise, cross-wind and vertical velocity components, respectively.

In ALEX17 we select the central position as a reference for atmospheric stability, and we use $z / L$ to evaluate the wind profiles under different stability conditions for two predominant wind directions. The $\mathrm{CP}$ is located on a plateau within the valley floor surrounded by farmland, which is one of the flattest and most homogeneous areas in the experimental area but still far from HHF conditions. The climatology of stability is derived by computing $z / L$ at $10 \mathrm{ma.g.l}$. from sonic anemometer measurements at $20 \mathrm{~Hz}$, computing the fluxes over $30 \mathrm{~min}$. We use the coordinate system described above by applying yaw and pitch rotations, i.e., double rotation. Table 2 shows the atmospheric stability classes given by $z / L$ intervals following the analysis by Berg et al. (2011) and the number of $30 \mathrm{~min}$ profiles. The $z / L$ parameter was chosen to classify stability from a climatological point of view. For the stratified flow patterns over complex terrain (Sect. 4), we select the Froude number since it is a more descriptive parameter for flow over obstacles (Kaimal and Finnigan, 1994).

The M7 3-D sonic anemometer closest to the surface is at $10 \mathrm{~m}$ a.g.l. One year of measurements (from August 2018 to July 2019) are available from this sonic anemometer with $84.6 \%$ of valid $30 \mathrm{~min}$ periods. Figure 7 a shows the daily cycle of dimensionless stability $10 / L$ at M7. As expected, stably stratified conditions prevail at night, whereas unstable conditions dominate during daytime and peak around midday. Figure $7 \mathrm{~b}$ shows the behavior of stability with wind speed, where a prevalence of neutral conditions with increasing wind speeds is found. We have also performed a similar analysis using the gradient Richardson number with concurrent wind speed observations from M7 and potential temperature profiles from windRASS. This parameter showed a similar distribution of stability classes in terms of diurnal cycle and wind speed bins (not shown).

Figure 8 presents the vertical profiles of the normalized mean wind speed for two prevalent wind sectors at the valley floor, namely a NW sector $\left(300 \pm 30^{\circ}\right)$ with $319330 \mathrm{~min}$ profiles in total and a SE sector $\left(120 \pm 30^{\circ}\right)$ with $312030 \mathrm{~min}$ profiles, both divided by stability classes. For each vertical level, the shaded area represents the standard error of the mean given by $\pm \sigma / \sqrt{N}$, where $\sigma$ is the SD and $N$ the number of observations. For the SE sector (Fig. 8a) large differences can be observed close to the surface, showing that the surface roughness' fetch can be quite inhomogeneous for this sector but also likely influenced by land-cover seasonal effects. Also, negative wind shears characterize the stable class, which are potentially caused by valley drainage flow (Serafin et al., 2018). Profiles from the NW wind sector (Fig. 8b) resemble more flat and homogeneous conditions, with increasing wind shear with stability and a similar normalized wind close to the surface except for stable conditions. 

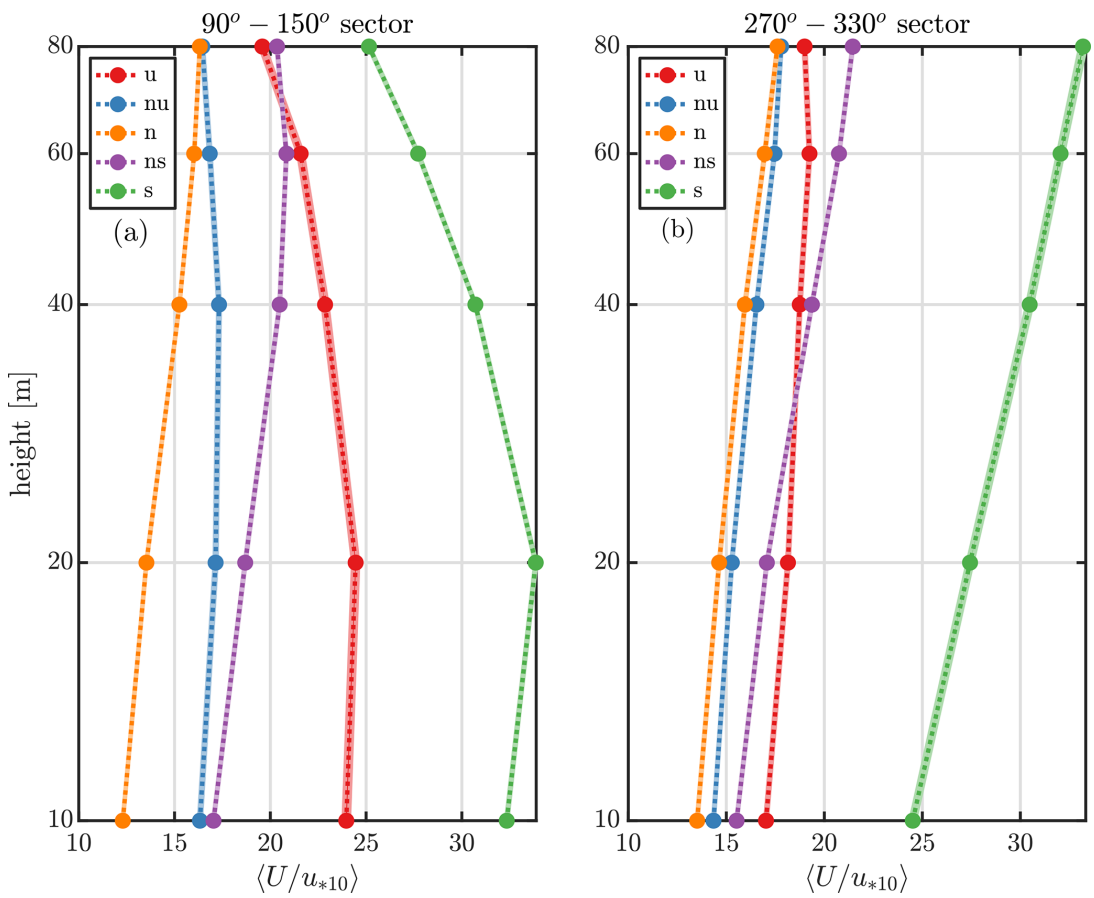

Figure 8. Mean vertical wind profiles normalized with the friction velocity computed by the 10 min sonic anemometer $\left(u_{* 10}\right)$. Panel (a) shows profiles within the $120 \pm 30^{\circ}$ sector, and panel (b) shows profiles within the $300 \pm 30^{\circ}$ sector based on wind directions at $10 \mathrm{~m}$. Shaded areas denote associated standard errors of the mean.

Furthermore, when dealing with mountain flows, the topography occupies a large portion of the ABL and hence plays a major role in the flow stratification. Disturbances in the stable atmosphere caused by the topography may generate three-dimensional flow phenomena, among others atmospheric lee waves, rotors and hydraulic jumps (Kaimal and Finnigan, 1994). The natural frequency of these vertical oscillations is characterized by the Brunt-Väisälä frequency $N=[(g / \bar{\theta})(\partial \bar{\theta} / \partial z)]^{1 / 2}$, where $\partial \bar{\theta} / \partial z$ is the potential temperature gradient. The potential temperature is computed as $\theta=T+0.0098 z_{\text {asl }}$, where $0.0098 \mathrm{Km}^{-1}$ is the dry adiabatic temperature gradient. The potential temperature gradient in $N$ is calculated by linear interpolation between the measurements at 2 and $80 \mathrm{~m}$ for M5/M3 and between 2 and $113 \mathrm{~m}$ for MP5.

The Froude number $(F r)$ is the dimensionless parameter given by the ratio of flow inertia based on a reference upwind wind speed $U$ to the gravity forces acting on the flow (Kaimal and Finnigan, 1994). Following the linearized solution presented by Rotunno and Lehner (2016) $F r=\pi U / 2 N D$, where $D$ is a height for the stably stratified flow layer upstream of the mountain, also called the inversion depth. The $\pi / 2$ multiplier comes from a derivation considering critical flow, i.e., $F r=1$. The scaling can also be performed with a characteristic mountain height $H$.

We choose the inversion depth $D$ to be proportional to the high wind speed layer height from the lidar measurements (cf. Fig. 9) and equal to $500 \mathrm{~m}$; i.e., it is an empirical se- lection based on this case study. The characteristic height $H$ is considered as the elevation difference between MP5 and M7, which is $\approx 500 \mathrm{~m}$; hence $H \sim D \approx 500 \mathrm{~m}$. $F r$ is evaluated at the Alaiz mountaintop (MP5) and foothills (M2), at the valley floor (M5) and at the north ridge slope (M3) using the same $D$. Furthermore, the characteristic wind speed $U$ is taken at $80 \mathrm{~m}$ at all positions.

It is worth noticing that the computation of $F r$ in this study has some caveats, as neither $U$ nor $N$ represent the entire inversion depth, and $D$ is a characteristic length with a somewhat arbitrary value. Here, our aim is to investigate the relative changes in $F r$, where we compare $F r$ estimations at the mountaintop with the ones along the valley.

\section{Selected flow cases}

\subsection{The lee-side hydraulic jump}

An atmospheric hydraulic jump occurs when a two-layer stratified flow encounters an obstacle and experiences an abrupt and turbulent transition in the flow layer depth and velocity, causing dissipation of kinetic energy in order to recover part of the original potential energy that existed upstream (Kaimal and Finnigan, 1994). It is assumed that the hydraulic theory can describe these high-amplitude mountain waves with downslope flow in the lee side (Baines, 1995). It differs from atmospheric gravity waves or lee waves since it involves a stronger discontinuity and requires non-linear 

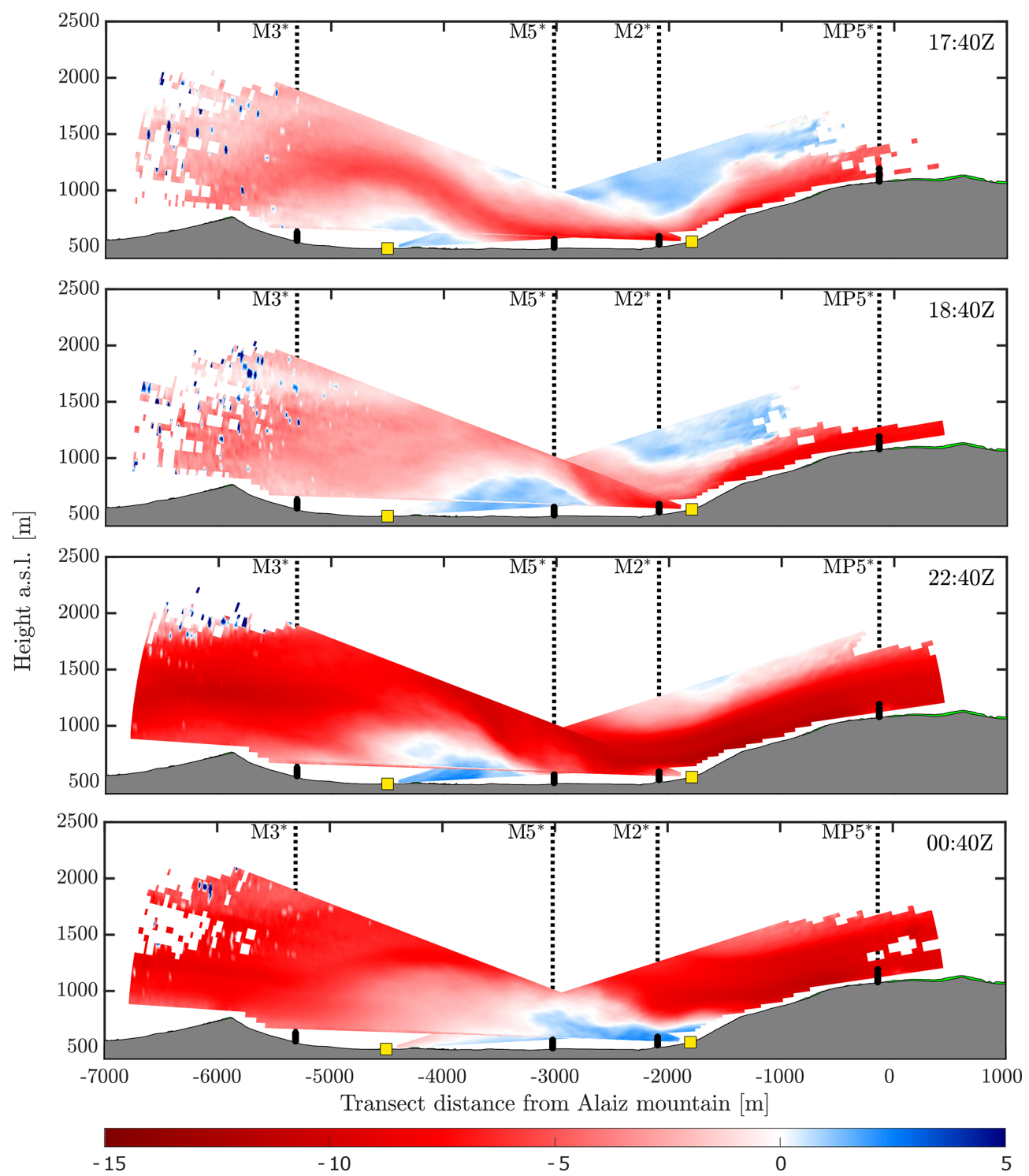

Figure 9. Superposition of dual RHI scans during the hydraulic jump period between 5-6 October 2018. The color bar represents radial wind speed in meters per second $\left(\mathrm{m} \mathrm{s}^{-1}\right)$ with negative values representing flow from right to left. Each of the frames correspond to a 10 min scan.

dynamics to be described, analogous to a shock wave when sound crosses the Mach number.

Long (1954) performed water tunnel experiments and his results show that the lee-side hydraulic jump occurs when the topographical feature is comparable to the depth of the upstream flow layer and there is a $\mathrm{Fr}$ transition between supercritical $(>1)$ at the mountaintop and subcritical $(<1)$ in the lee side. The solutions presented by Houghton and Kasahara (1968) and Vosper (2004) also predicted under which conditions the jump occurs, based on $H, D$ and a $F r$ scaled with the maximum wave speed given by $\sqrt{g^{\prime} D}$, where $g^{\prime}$ is a reduced gravitational acceleration.

METCRAX II identified jump-like episodes using coplanar RHI lidars scans (Lehner et al., 2016). Whiteman et al.
(2018) used the latter lidar measurements to propose a conceptual model of the jump, yet limited to the scales and particularities of the meteorite crater case study. Rotunno and Bryan (2018) further performed numerical simulations of a steady-state jump considering the full time-dependent threedimensional flow description. Results quantify the jump's evolution and structure based on potential temperature, vorticity and turbulent kinetic energy.

We defined $H \sim D \approx 500 \mathrm{~m}$ in Sect. 3.2, which is arbitrary using observations from this episode. Therefore, this choice can produce variations in the Froude number. Figure 9 shows four $10 \mathrm{~min}$ periods of co-planar RHIs during one night where a hydraulic jump was spotted at the lee side of the Alaiz mountain between 5 and 6 October 2018 . 

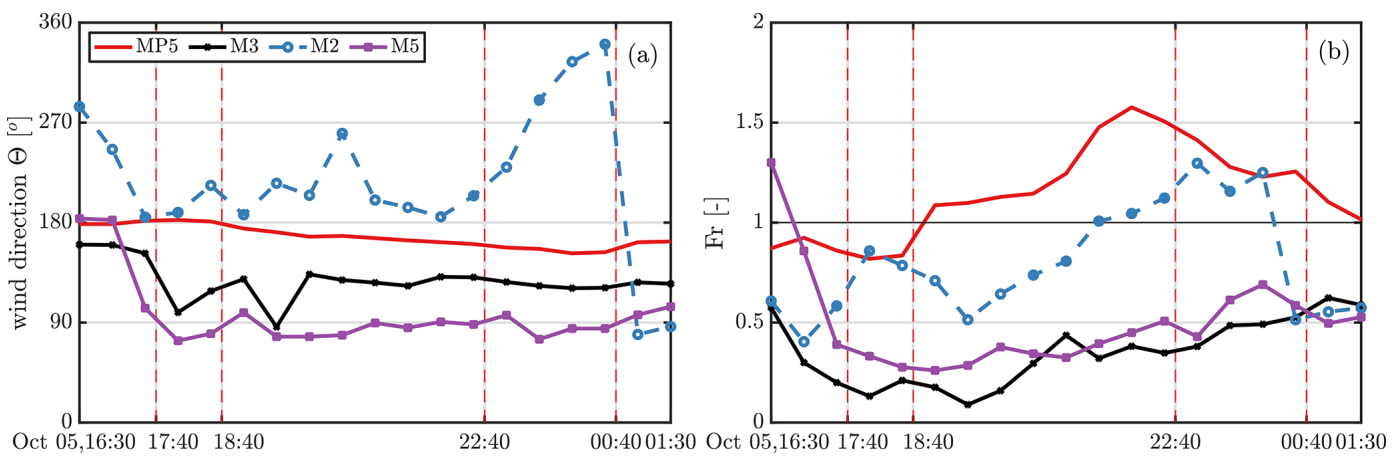

Figure 10. Time series of wind direction (a) and Froude number (b) during the hydraulic jump case. The vertical dashed lines represent the snapshots of Fig. 9.

The main southerly flow has negative radial wind speeds, indicated by red colors, where a strong downslope wind reaches the valley and performs the jump, which is nonsteady as the jump location changes with time. Long (1954) also argued that when $\mathrm{Fr}$ decreases at the obstacle, the jump moves towards the obstacle (mountain) and loses intensity. Conversely, when $\mathrm{Fr}$ increases at the obstacle, the jump moves further downstream and becomes more intense.

Figure 10 compares the wind direction regimes and $\mathrm{Fr}$ numbers between the masts located at the mountaintop (MP5), mountain foothills (M2), valley floor (M5) and north ridge's slope (M3). The M7 mast did not have valid temperature measurements during this period; hence it is not shown. The southerly flow is maintained at MP5 throughout the period, with easterly winds at the jump's location. We observe a transition between $F r>1$ at the mountaintop to $F r<1$ at the valley. According to Long (1954), the supercritical to subcritical transition is strong evidence for the onset of a hydraulic jump, which is confirmed herein as well as in smallerscale experiments (Rotunno and Lehner, 2016).

Furthermore, the time evolution of the hydraulic jump described by Long (1954) is also confirmed in this episode. Between 18:40 and 22:40 Z the jump tends to move further downstream as $F r$ at MP5 goes from 1 to 1.5. From 22:40 to 00:40 Z the flow loses intensity, the jump moves towards the mountain while $F r$ at MP5 decreases from 1.5 to 1.2, and the M2 measurements, in the lower portion of the hydraulicjump rotor, evidence reverse surface winds (Strauss et al., 2016). Nonetheless, towards the end of this episode the lidar measurements cease to show strong downslope winds into the valley. The last scan of Fig. 9 suggests that the flow tends to evolve to a lee-wave-type rotor, with $F r$ closer to critical at the mountaintop (cf. Fig. 10b) and less of a closed rotor circulation downstream.

Figure 11a shows a $10 \mathrm{~min}$ average snapshot (19:00 Z) of the hydraulic jump episode, with wind and temperature measurements from the surface-layer stations. The stratified southerly winds close to the surface enter the Elorz valley surrounding the Alaiz mountain through the eastern side. The flow at the center of the valley (from S3, S8, S1 and S2) is from the east. The wind speed from the along-valley stations also shows the effect of topographical channeling; i.e., the wind decelerates as the valley becomes wider. On the other hand, the flow along the Alaiz slopes comes from the south (see S5, S4 and S6) and remains almost steady along the night. Wind at the northern part of the valley is weak, which is also observed by the lidar scans, and the air stratification is more intense, as shown by S7 and S9, located downstream the hydraulic jump.

Figure $11 \mathrm{~b}$ shows the same $10 \mathrm{~min}$ snapshot (19:00 Z) of wind speed and direction profiles from S1, M7, M5 and windRASS at the central position. The instruments at the $\mathrm{CP}$ agree and show weak easterly winds. Additionally, the wind speed profile at M5 further highlights the valley channeling effect, with measurements located $1 \mathrm{~km}$ east and $20 \mathrm{~m}$ below CP. The potential temperature profiles (Fig. 11c) from S1, M5, and windRASS agree and show a thermal inversion. The presence of a stratified valley floor with stagnant flow agrees with similar observations of METCRAX II (Lehner et al., 2016) but here in a horizontal scale 10 times larger.

This case shows that the lee-side hydraulic jump is characterized by a $F r$ transition from supercritical $F r>1$ at the mountain to subcritical $F r<1$ at the valley floor. After inspecting the entire year period with concurrent data from MP5 (mountaintop) and M5 (valley floor), approximately $35 \%$ of all the stably stratified periods reproduce a similar $\mathrm{Fr}$ transition. Thus, considering only southerly winds, the occurrence of the hydraulic jump could reach $10 \%$ of the time, suggesting that the current dataset could be suitable for a deeper study on such phenomena.

\subsection{Layered flow induced by valley winds}

During the hydraulic jump we have seen how winds at the valley characterized the jump's recirculation zone. Disparately, with low wind speeds thermal stratification over mountainous terrain can modulate flow patterns (Jiménez et al., 2019) which, together with a heterogeneous land cover, causes unequal heat fluxes (Martínez et al., 2010). Grubišić 

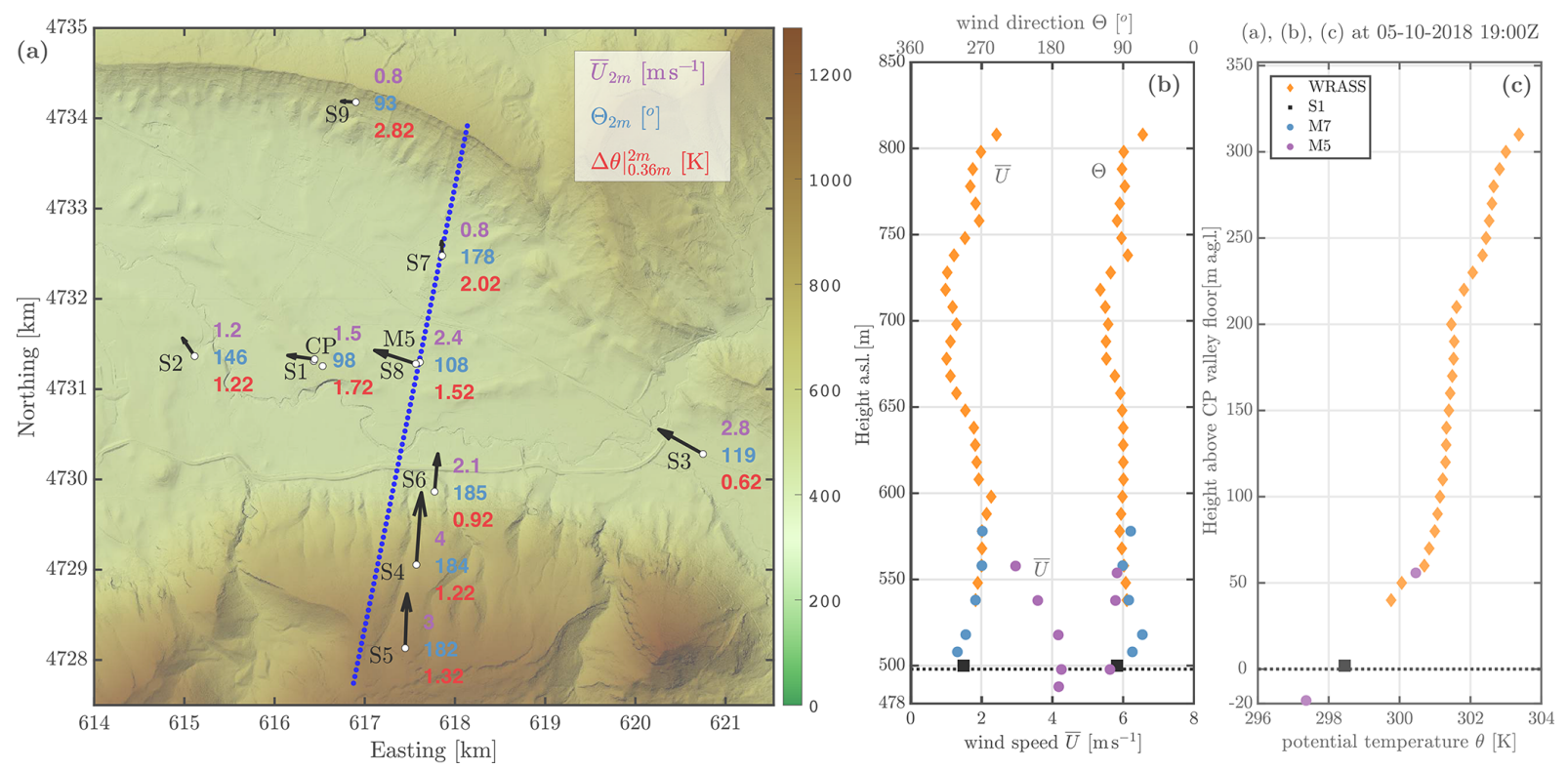

Figure 11. Wind conditions during the hydraulic jump case on 5 October 2018 at 19:00 Z. Panel (a) shows surface-layer stations' wind speed $\left(\bar{U}_{2 \mathrm{~m}}\right)$ and wind direction $\left(\Theta_{2 \mathrm{~m}}\right)$, both at $2 \mathrm{~m}$ and potential temperature gradient between 0.36 and $2 \mathrm{~m}(\Delta \theta)$. Panels $(\mathbf{b})$ and $(\mathbf{c})$ show vertical profiles of wind and potential temperature at the valley from the windRASS, M7, S1 and M5. The dashed line marks the valley floor level at CP.

et al. (2008) showed a three-layer flow structure in a valleymountain region under quiescent conditions, where up-valley and down-valley winds are thermally driven and decoupled from the mesoscale flow aloft. ALEX17 also presents valley winds that develop into layered stratified flows.

An example is found during the night of 24 to 25 October 2018. For this case, the synoptic situation is dominated by a strong wind of northern component whose intensity starts to decrease several hours after sunset. Closer to the surface, this general wind takes a western direction within the Elorz valley. Figure 12a shows four 10 min periods of the co-planar RHI scans representative of the evolution of the layered flows within the valley. As in Fig. 9, the positive radial wind speeds represent flow from left to right. Figure $12 \mathrm{~b}$ displays the corresponding potential temperature profiles measured by the windRASS and M5 at the valley center, where the air becomes cooler close to the surface and a thermal inversion develops along the night, becoming very intense after midnight.

Before sunset $(\approx 17: 00 \mathrm{Z})$, the northwesterly flow within the valley is coupled with stronger mountain winds aloft as shown by the first lidar scan. A weak stably stratified layer develops after sunset and surface winds adjust to a new equilibrium where the valley topography has a major influence. This layer depth increases as the thermal inversion develops within the valley, producing a layering effect as seen by the subsequent RHI scans at 22:10 and 00:10 Z (Fig. 12a). Southwesterly winds are present at the valley floor and over the southern slopes, while a northwesterly flow remains within the valley atmosphere aloft, still coupled with the mesoscale wind. Both layers are stably stratified although with different intensity. The thermal stratification at the upper layer remains steady along the night, while the surface inversion evolves very slowly until midnight (Fig. 12b).

Figure 13a shows a $10 \mathrm{~min}$ average snapshot (22:30 Z) of the valley winds measured by the surface-layer stations, indicating the southerly component of the wind at the valley center and over the southern slope within the surface layer, as well as the increment of the wind speed as the valley gets narrower towards the east. The S7 and S9 positions show a sheltered zone in the lee side of the north ridge, where the wind is very weak together with the strongest surface thermal inversion.

Figure $13 \mathrm{~b}$ and $\mathrm{c}$ represent the wind speed and wind direction measured at MP5 118 and at $80 \mathrm{ma}$ a.g.l. by distinct masts across the valley. There is a persistent offset of $90^{\circ}$ in the wind direction between the mountain (MP5) and valley (M2, M3, M5), while the general wind decreases throughout the evening, as indicated by MP5. In consequence, the wind speed also diminishes within the valley, intensifying the surface cooling and generating a stronger thermal inversion at the valley floor after midnight (Fig. 12b). This situation favors the development of a cold-air pool (Serafin et al., 2018) which decouples the surface layer, with winds responding to a local regime, from the southwesterly flow within the valley (not shown). An elevated thermal inversion around 720 ma.s.l. (see profile at 03:10 Z in Fig. 12b) decouples the valley atmosphere from the northerly wind aloft, increasing the depth of the red band within the valley observed in the RHI scan at 03:10Z (Fig. 12a). 

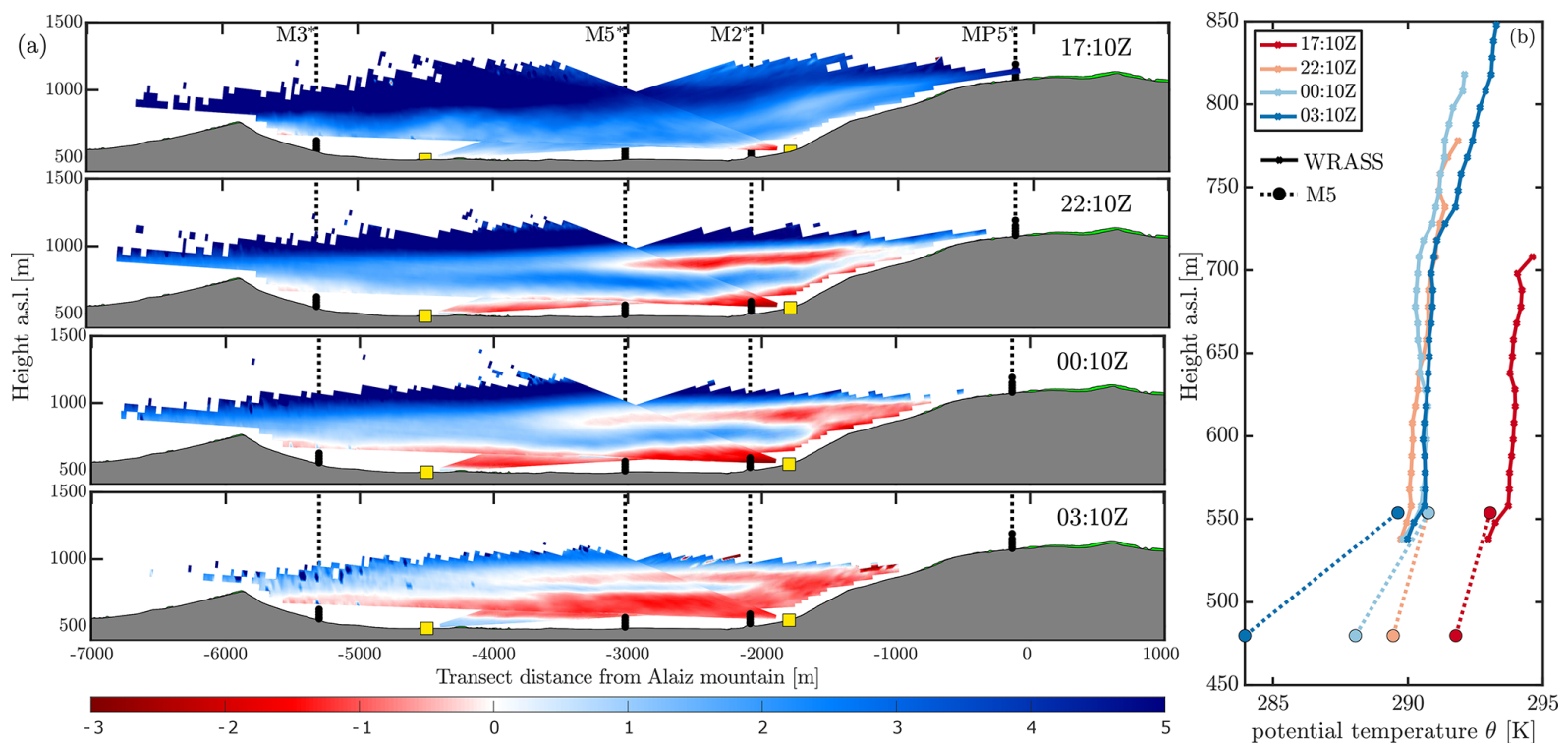

Figure 12. Panel (a) shows the superposition of dual RHI scans during the layered valley winds period between 24-25 October 2018. Panel (b) shows the potential temperature profiles measured by the windRASS and M5 at each frame in panel (a).
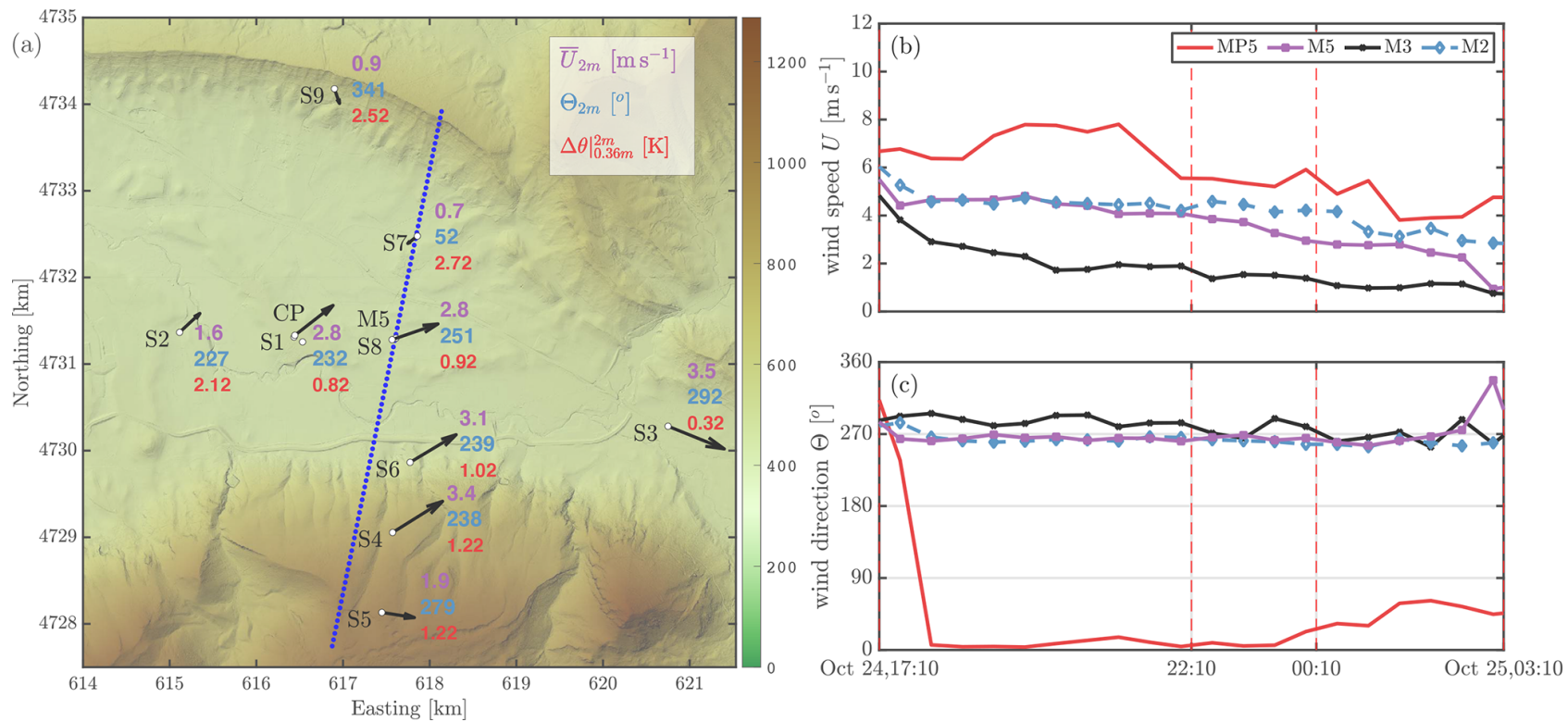

Figure 13. Panel (a) shows surface-layer stations' wind speed $\left(\bar{U}_{2 \mathrm{~m}}\right)$ and wind direction $\left(\Theta_{2 \mathrm{~m}}\right)$, both at $2 \mathrm{~m}$ and potential temperature gradient between 0.36 and $2 \mathrm{~m}(\Delta \theta)$ at 24 October 2018 22:30 Z. Panels (b) and (c) show the time series of wind speed and direction from the masts, respectively. The vertical dashed lines represent the snapshots of Fig. 12.

\section{Summary and conclusions}

This work introduces the Alaiz experiment (ALEX17) with details on the main innovations in atmospheric measurements, unique characteristics and two flow patterns observed during the 8-month Intensive Observational Period (IOP). ALEX17 is in a striking position in terms of scale and complexity. The experimental domain is large enough for synop- tic effects to be essential for flow modeling while still being within the range of current long-range commercial lidars.

Additionally, ALEX17 requires the adoption of meso- to microscale models. Palma et al. (2019) showed advancements in such modeling schemes during the Perdigão experiment, especially for stably stratified flows. ALEX17 yet poses a further challenge in numerical modeling efforts because of its large domain size. 
The topographical features of ALEX17, with a nonparallel mountain-valley-ridge configuration, lead to the occurrence of valley winds with quite distinct wind regimes from the mountaintop, where wind rotates by up to $90^{\circ}$ and channeling effects are observed. To capture most of the wind flow spatial variability, five scanning Doppler lidars performed synchronized measurements of a unique $10 \mathrm{~km}$ transect line, covering a vast portion of the experimental domain. The experimental report (Cantero et al., 2019) offers further technical information on the campaign and dataset.

Wind measurements at the mountaintop are available since 2011; nevertheless ALEX17's 2-year extensive measurement campaign has been able to represent the wind climatology well. When comparing available mesoscale modeling from the New European Wind Atlas with observations, a negative bias in the mean wind larger than $1.5 \mathrm{~m} \mathrm{~s}^{-1}$ pointed to the need of further improvement of model performance at this site. At the valley floor, vertical wind profiles with southeasterly winds showed negative wind shear under stable conditions, whereas for northwesterly wind profiles are more canonical but still affected by land-cover inhomogeneities.

Using the multi-lidar scans we spotted a lee-side atmospheric hydraulic jump episode. Measurements from masts and surface-layer stations corroborated the formation and evolution of the jump with long-established predictions (Long, 1954). The Froude number transition from supercritical $(>1)$ to subcritical $(<1)$ was quantified and results suggest that this type of stratified atmospheric wave can potentially happen during $\approx 10 \%$ of the time in this site.
The hydraulic jump is connected with high southerly winds at the mountaintop. On the other hand, during stratified conditions with lower wind speeds, valley winds become decoupled from the mountain flow aloft due to thermal stratification, favoring the formation of a cold-air pool very close to the surface (Martínez et al., 2010; Conangla et al., 2018). This case is illustrated with a layered flow pattern measured by the lidar scans, where westerly stratified valley winds interact with northerly winds aloft. Other atmospheric phenomena captured within the IOP shall be the object of further studies.

We have characterized two multi-scale stratified flows regarded as challenging in terms of both their physical description (Serafin et al., 2018) and modeling (Sanz Rodrigo et al., 2017). Other flow episodes, featuring, among others, upstream flow blockage and lee waves, were spotted and can be the object of further studies. These measurements will provide aid to evaluate numerical models especially for testing the effects of atmospheric stability on flow over complex terrain. 
Appendix A: Lidar configuration for RHI transect

scan

Table A1. WindScanner position and configuration for the transect RHI scans.

\begin{tabular}{|c|c|c|}
\hline Parameters & WS3 & WS5 \\
\hline (easting, northing) [m] & $(617846.80,4732496.43)$ & $(617305.59,4729848.75)$ \\
\hline Elevation [ma.s.1] & 487.21 & 545.92 \\
\hline Azimuth $\left[{ }^{\circ}\right]$ & 191.55 & 11.55 \\
\hline Elevation $(\min , \max )\left[^{\circ}\right]$ & $(3,18)$ & $(1.58,21.56)$ \\
\hline Scan speed $\left[{ }^{0-1}\right]$ & 0.5 & 0.666 \\
\hline Range gates (min: $\Delta: \max )[\mathrm{m}]$ & $(100: 50: 5000)$ & $(100: 20: 5000)$ \\
\hline Accumulation time $[\mathrm{ms}]$ & \multicolumn{2}{|c|}{1000} \\
\hline Pulse length [ns] & \multicolumn{2}{|c|}{400} \\
\hline Points per range gate $[-]$ & \multicolumn{2}{|c|}{128} \\
\hline Signal spectral width $\left[\mathrm{m} \mathrm{s}^{-1}\right]$ & \multicolumn{2}{|c|}{3} \\
\hline Specified physical resolution [m] & \multicolumn{2}{|c|}{75} \\
\hline
\end{tabular}


Data availability. The Alaiz experiment dataset collected during the EMP is publicly available and can be found in Santos et al. (2019), with metadata and citation guidelines for each group of instruments.

Supplement. The supplement related to this article is available online at: https://doi.org/10.5194/wes-5-1793-2020-supplement.

Author contributions. The funding was acquired and the project was administrated by JM, JSR, JC and EC, while JM, JSR, EC, PS, NV, JC and DMV conceptualized the experiment and analysis. PS, DMV, FB and EC curated the data, while the methodology was devised by PS, NV and DMV. The analysis and visualization was performed by PS and BM. PS wrote the original draft, while PS, JM, NV, EC, JSR, FB, DMV, BM and JC contributed, reviewed and edited the final paper.

Competing interests. The authors declare that they have no conflict of interest.

Acknowledgements. We would like to thank Michael Courtney and all staff from DTU Wind Energy (Denmark), CENER and UIB (Spain) involved on the commissioning and ongoing monitoring of the experimental infrastructure. We credit Alfredo Peña for reviewing the manuscript and for the analysis that resulted in Fig. 1. We would also like to thank Ebba Dellwik for her guidance during the manuscript writing, Bianca Adler for her useful comment during the open discussion and two anonymous referees for a thorough review.

Financial support. This research has been supported by the New European Wind Atlas (NEWA) joint program (grant no. 618122). Belén Martí was supported by the grant FPI-CAIB (FPI/2165/2018) of the Vicepresidència i Conselleria d'Innovació, Recerca i Turisme del Govern de les Illes Balears and the Fons Social Europeu. The windRASS and SEB station were rented from the Meteorological Service of Catalonia with funds of the research project PCIN-2014016-C07-01.

Review statement. This paper was edited by Rebecca Barthelmie and reviewed by two anonymous referees.

\section{References}

Adler, B., Gohm, A., Kalthoff, N., Babić, N., Corsmeier, U., Lehner, M., Rotach, M. W., Haid, M., Markmann, P., Gast, E., Tsaknakis, G., and Georgoussis, G.: CROSSINN - a field experiment to study the three-dimensional flow structure in the Inn Valley, Austria, B. Am. Meteorol. Soc., 1-55, https://doi.org/10.1175/BAMS-D-19-0283.1, 2020.

Badger, J., Frank, H., Hahmann, A. N., and Giebel, G.: Wind-climate estimation based on mesoscale and microscale modeling: Statistical-dynamical downscaling for wind energy applications, J. Appl. Meteorol. Clim., 53, 1901-1919, https://doi.org/10.1175/JAMC-D-13-0147.1, 2014.

Baines, P. G.: Topographic Effects in Stratified Flows, Cambridge University Press, Cambridge, 1995.

Bechmann, A., Sørensen, N. N., Berg, J., Mann, J., and Réthoré, P. E.: The Bolund Experiment, Part II: Blind Comparison of Microscale Flow Models, Bound.-Lay. Meteorol., 141, 245-271, https://doi.org/10.1007/s10546-011-9637-x, 2011.

Berg, J., Mann, J., Bechmann, A., Courtney, M. S., and Jørgensen, H. E.: The Bolund Experiment, Part I: Flow Over a Steep, Three-Dimensional Hill, Bound.-Lay. Meteorol., 141, 219-243, https://doi.org/10.1007/s10546-011-9636-y, 2011.

Cantero, E., Borbón Guillén, F., Sanz Rodrigo, J., Santos, P., Mann, J., Vasiljević, N., Courtney, M., Martínez Villagrasa, D., Martí, B., and Cuxart, J.: Alaiz Experiment (ALEX17): Campaign and Data Report, Tech. Rep. May, CENER, DTU and UIB, Zenodo, https://doi.org/10.5281/zenodo.3187482, 2019.

Chavez Arroyo, R. A.: ALEX17 high-resolution, digital information of topography, surface and aerodynamic roughness of the experimental domain, Technical University of Denmark, Roskilde, Denmark, https://doi.org/10.11583/DTU.8143775.v1, 2019.

Conan, B., Chaudhari, A., Aubrun, S., van Beeck, J., Hämäläinen, J., and Hellsten, A.: Experimental and Numerical Modelling of Flow over Complex Terrain: The Bolund Hill, Bound.-Lay. Meteorol., 158, 183-208, https://doi.org/10.1007/s10546-015-0082$0,2016$.

Conangla, L., Cuxart, J., Jiménez, M. A., Martínez-Villagrasa, D., Miró, J. R., Tabarelli, D., and Zardi, D.: Cold-air pool evolution in a wide Pyrenean valley, Int. J. Climatol., 38, 2852-2865, https://doi.org/10.1002/joc.5467, 2018.

Coppin, P. A., Bradley, E. F., and Finnigan, J. J.: Measurements of flow over an elongated ridge and its thermal stability dependence: The mean field, Bound.-Lay. Meteorol., 69, 173-199, https://doi.org/10.1007/BF00713302, 1994.

Cuxart, J., Cunillera, J., Jiménez, M. A., Martínez, D., Molinos, F., and Palau, J. L.: Study of Mesobeta Basin Flows by Remote Sensing, Bound.-Lay. Meteorol., 143, 143-158, https://doi.org/10.1007/s10546-011-9655-8, 2012.

Cuxart, J., Conangla, L., and Jiménez, M. A.: Evaluation of the surface energy budget equation with experimental data and the ECMWF model in the Ebro Valley, J. Geophys. Res., 120, 10081022, https://doi.org/10.1002/2014JD022296, 2015.

Dörenkämper, M., Olsen, B. T., Witha, B., Hahmann, A. N., Davis, N. N., Barcons, J., Ezber, Y., García-Bustamante, E., GonzálezRouco, J. F., Navarro, J., Sastre-Marugán, M., Sīle, T., Trei, W., Žagar, M., Badger, J., Gottschall, J., Sanz Rodrigo, J., and Mann, J.: The Making of the New European Wind Atlas - Part 2: 
Production and evaluation, Geosci. Model Dev., 13, 5079-5102, https://doi.org/10.5194/gmd-13-5079-2020, 2020.

Fernando, H. J., Pardyjak, E. R., Di Sabatino, S., Chow, F. K., De Wekker, S. F., Hoch, S. W., Hacker, J., Pace, J. C., Pratt, T., Pu, Z., Steenburgh, W. J., Whiteman, C. D., Wang, Y., Zajic, D., Balsley, B., Dimitrova, R., Emmitt, G. D., Higgins, C. W., Hunt, J. C., Knievel, J. C., Lawrence, D., Liu, Y., Nadeau, D. F., Kit, E., Blomquist, B. W., Conry, P., Coppersmith, R. S., Creegan, E., Felton, M., Grachev, A., Gunawardena, N., Hang, C., Hocut, C. M., Huynh, G., Jeglum, M. E., Jensen, D., Kulandaivelu, V., Lehner, M., Leo, L. S., Liberzon, D., Massey, J. D., McEnerney, K., Pal, S., Price, T., Sghiatti, M., Silver, Z., Thompson, M., Zhang, H., and Zsedrovits, T.: The MATERHORN: Unraveling the intricacies of mountain weather, B. Am. Meteorol. Soc., 96, 1945-1968, https://doi.org/10.1175/BAMSD-13-00131.1, 2015.

Fernando, H. J. S., Mann, J., Palma, J. M. L. M., Lundquist, J. K., Barthelmie, R. J., Belo-Pereira, M., Brown, W. O. J., Chow, F. K., Gerz, T., Hocut, C. M., Klein, P. M., Leo, L. S., Matos, J. C., Oncley, S. P., Pryor, S. C., Bariteau, L., Bell, T. M., Bodini, N., Carney, M. B., Courtney, M. S., Creegan, E. D., Dimitrova, R., Gomes, S., Hagen, M., Hyde, J. O., Kigle, S., Krishnamurthy, R., Lopes, J. C., Mazzaro, L., Neher, J. M. T., Menke, R., Murphy, P., Oswald, L., Otarola-Bustos, S., Pattantyus, A. K., Rodrigues, C. V., Schady, A., Sirin, N., Spuler, S., Svensson, E., Tomaszewski, J., Turner, D. D., van Veen, L., Vasiljević, N., Vassallo, D., Voss, S., Wildmann, N., and Wang, Y.: The Perdigão: Peering into Microscale Details of Mountain Winds, B. Am. Meteorol. Soc., 100, 799-819, https://doi.org/10.1175/bams-d-17-0227.1, 2019.

Foken, T.: 50 years of the Monin-Obukhov similarity theory, Bound.-Lay. Meteorol., 119, 431-447, https://doi.org/10.1007/s10546-006-9048-6, 2006.

Grubišić, V., Doyle, J. D., Kuettner, J., Mobbs, S., Smith, R. B., Whiteman, C. D., Dirks, R., Czyzyk, S., Cohn, S. A., Vosper, S., Weissmann, M., Haimov, S., De Wekker, S. F. J., Pan, L. L., and Chow, F. K.: The Terrain-Induced Rotor Experiment, B. Am. Meteorol. Soc., 89, 1513-1534, https://doi.org/10.1175/2008BAMS2487.1, 2008.

Hahmann, A. N., Sīle, T., Witha, B., Davis, N. N., Dörenkämper, M., Ezber, Y., García-Bustamante, E., González-Rouco, J. F., Navarro, J., Olsen, B. T., and Söderberg, S.: The making of the New European Wind Atlas - Part 1: Model sensitivity, Geosci. Model Dev., 13, 5053-5078, https://doi.org/10.5194/gmd-135053-2020, 2020.

Haid, M., Gohm, A., Umek, L., Ward, H. C., Muschinski, T., Lehner, L., and Rotach, M. W.: Foehn-cold pool interactions in the Inn Valley during PIANO IOP2, Q. J. Roy. Meteorol. Soc., 146, 1232-1263, https://doi.org/10.1002/qj.3735, 2020.

Haupt, S. E., Kosovic, B., Shaw, W., Berg, L. K., Churchfield, M., Cline, J., Draxl, C., Ennis, B., Koo, E., Kotamarthi, R., Mazzaro, L., Mirocha, J., Moriarty, P., Muñoz-Esparza, D., Quon, E., Rai, R. K., Robinson, M., and Sever, G.: On bridging a modeling scale gap: Mesoscale to microscale coupling for wind energy, B. Am. Meteorol. Soc., 100, 2533-2549, https://doi.org/10.1175/BAMSD-18-0033.1, 2019.

Houghton, D. D. and Kasahara, A.: Nonlinear shallow fluid flow over an isolated ridge, Commun. Pure Appl. Math., 21, 1-23, https://doi.org/10.1002/cpa.3160210103, 1968.
Jiménez, M. A., Cuxart, J., and Martínez-Villagrasa, D.: Influence of a valley exit jet on the nocturnal atmospheric boundary layer at the foothills of the Pyrenees, Q. J. Roy. Meteorol. Soc., 145, 356-375, https://doi.org/10.1002/qj.3437, 2019.

Jiménez, P. A., González-Rouco, J. F., Montávez, J. P., GarcíaBustamante, E., Navarro, J., and Dudhia, J.: Analysis of the longterm surface wind variability over complex terrain using a high spatial resolution WRF simulation, Clim. Dynam., 40, 16431656, https://doi.org/10.1007/s00382-012-1326-z, 2013.

Kaimal, J. C. and Finnigan, J. J.: Atmospheric boundary layer flows: their structure and measurement, Oxford University Press, New York, 1994.

Kilpatrick, R., Hangan, H., Siddiqui, K., Parvu, D., Lange, J., Mann, J., and Berg, J.: Effect of Reynolds number and inflow parameters on mean and turbulent flow over complex topography, Wind Energ. Sci., 1, 237-254, https://doi.org/10.5194/wes-1-237-2016, 2016.

Lange, J., Mann, J., Angelou, N., Berg, J., Sjöholm, M., and Mikkelsen, T.: Variations of the Wake Height over the Bolund Escarpment Measured by a Scanning Lidar, Bound.-Lay. Meteorol., 159, 147-159, https://doi.org/10.1007/s10546-015-0107-8, 2016.

Lange, J., Mann, J., Berg, J., Parvu, D., Kilpatrick, R., Costache, A., Chowdhury, J., Siddiqui, K., and Hangan, H.: For wind turbines in complex terrain, the devil is in the detail, Environ. Res. Lett., 12, 094020, https://doi.org/10.1088/1748-9326/aa81db, 2017.

Lehner, M., Whiteman, C. D., Hoch, S. W., Crosmsman, E. T., Jeglum, M. E., Cherukuru, N. W., Calhoun, R., Adler, B., Kalthoff, N., Rotunno, R., Horst, T. W., Semmmmer, S., Brown, W. O., Oncley, S. P., Vogt, R., Grudzielanek, A. M., Cermak, J., Fonteyne, N. J., Bernhofer, C., Pitacco, A., and Klein, P.: The METCRAX II Field Experiment: A Study of Downslope Windstorm-Type Flows in Arizona's Meteor Crater, B. Am. Meteorol. Soc., 97, 217-235, https://doi.org/10.1175/BAMS-D-1400238.1, 2016.

Long, R. R.: Some Aspects of the Flow of Stratified Fluids: II. Experiments with a Two-Fluid System, Tellus, 6, 97-115, https://doi.org/10.3402/tellusa.v6i2.8731, 1954.

Mann, J., Angelou, N., Arnqvist, J., Callies, D., Cantero, E., Arroyo, R. C., Courtney, M., Cuxart, J., Dellwik, E., Gottschall, J., Ivanell, S., Kühn, P., Lea, G., Matos, J. C., Palma, J. M. L. M., Pauscher, L., Peña, A., Rodrigo, J. S., Söderberg, S., Vasiljevic, N., and Rodrigues, C. V.: Complex terrain experiments in the New European Wind Atlas, Philos. T. Roy. Soc. A, 375, 20160101, https://doi.org/10.1098/rsta.2016.0101, 2017.

Martínez, D., Jiménez, M. A., Cuxart, J., and Mahrt, L.: Heterogeneous nocturnal cooling in a large basin under very stable conditions, Bound.-Lay. Meteorol., 137, 97-113, https://doi.org/10.1007/s10546-010-9522-z, 2010.

Menke, R., Vasiljević, N., Mann, J., and Lundquist, J. K.: Characterization of flow recirculation zones at the Perdigão site using multi-lidar measurements, Atmos. Chem. Phys., 19, 2713-2723, https://doi.org/10.5194/acp-19-2713-2019, 2019.

Olsen, B. T., Hahmann, A. N., Sempreviva, A. M., Badger, J., and Jørgensen, H. E.: An intercomparison of mesoscale models at simple sites for wind energy applications, Wind Energ. Sci., 2, 211-228, https://doi.org/10.5194/wes-2-211-2017, 2017.

Palma, J. M., Silva Lopes, A., Costa Gomes, V. M., Veiga Rodrigues, C., Menke, R., Vasiljević, N., and Mann, J.: Unravel- 
ling the wind flow over highly complex regions through computational modeling and two-dimensional lidar scanning, J. Phys.: Conf. Ser., 1222, 012006, https://doi.org/10.1088/17426596/1222/1/012006, 2019.

Pauscher, L., Vasiljevic, N., Callies, D., Lea, G., Mann, J., Klaas, T., Hieronimus, J., Gottschall, J., Schwesig, A., Kühn, M., and Courtney, M.: An Inter-Comparison Study of Multi- and DBS Lidar Measurements in Complex Terrain, Remote Sens.-Basel, 8, 782, https://doi.org/10.3390/rs8090782, 2016.

Rotunno, R. and Bryan, G. H.: Numerical Simulations of Two-Layer Flow past Topography. Part I: The Leeside Hydraulic Jump, J. Atmos. Sci., 75, 1231-1241, https://doi.org/10.1175/jas-d-17-0306.1, 2018.

Rotunno, R. and Lehner, M.: Two-Layer Stratified Flow past a Valley, J. Atmos. Sci., 73, 4065-4076, https://doi.org/10.1175/JASD-16-0132.1, 2016.

Salmon, J. R., Bowen, A. J., Hoff, A. M., Johnson, R., Mickle, R. E., Taylor, P. A., Tetzlaff, G., and Walmsley, J. L.: The Askervein Hill Project: Mean wind variations at fixed heights above ground, Bound.-Lay. Meteorol., 43, 247-271, https://doi.org/10.1007/BF00128406, 1988.

Santos, P., Mann, J., Vasiljevic, N., Courtney, M., Sanz Rodrigo, J., Cantero, E., Borbón, F., Martínez-Villagrasa, D., Martí, B., and Cuxart, J.: The Alaiz Experiment (ALEX17): wind field and turbulent fluxes in a large-scale and complex topography with synoptic forcing, Technical University of Denmark, Roskilde, Denmark, https://doi.org/10.11583/DTU.c.4508597.v1, 2019.

Sanz Rodrigo, J., Borbón Guillén, F., Gómez Arranz, P., Courtney, M. S., Wagner, R., and Dupont, E.: Multisite testing and evaluation of remote sensing instruments for wind energy applications, Renew. Energ., 53, 200-210, https://doi.org/10.1016/j.renene.2012.11.020, 2013.

Sanz Rodrigo, J., Chávez Arroyo, R. A., Moriarty, P., Churchfield, M., Kosović, B., Réthoré, P. E., Hansen, K. S., Hahmann, A., Mirocha, J. D., and Rife, D.: Mesoscale to microscale wind farm flow modeling and evaluation, WIREs Energy Environ., 6, https://doi.org/10.1002/wene.214, 2017.

Serafin, S., Adler, B., Cuxart, J., De Wekker, S. F., Gohm, A., Grisogono, B., Kalthoff, N., Kirshbaum, D. J., Rotach, M. W., Schmidli, J., Stiperski, I., Večenaj, Ž., and Zardi, D.: Exchange processes in the atmospheric boundary layer over mountainous terrain, Atmosphere, 9, 1-32, https://doi.org/10.3390/atmos9030102, 2018.
Simó, G., Cuxart, J., Jiménez, M. A., Martínez-Villagrasa, D., Picos, R., López-Grifol, A., and Martí, B.: Observed Atmospheric and Surface Variability on Heterogeneous Terrain at the Hectometer Scale and Related Advective Transports, J. Geophys. Res.-Atmos., 124, 9407-9422, https://doi.org/10.1029/2018JD030164, 2019.

Strauss, L., Serafin, S., and Grubišić, V.: Atmospheric Rotors and Severe Turbulence in a Long Deep Valley, J. Atmos. Sci., 73, 1481-1506, https://doi.org/10.1175/JAS-D-15-0192.1, 2016.

Vasiljević, N., Lea, G., Courtney, M., Cariou, J. P., Mann, J., and Mikkelsen, T.: Long-range WindScanner system, Remote Sens.Basel, 8, 1-24, https://doi.org/10.3390/rs8110896, 2016.

Vasiljević, N., L. M. Palma, J. M., Angelou, N., Carlos Matos, J., Menke, R., Lea, G., Mann, J., Courtney, M., Frölen Ribeiro, L., and M. G. C. Gomes, V. M.: Perdigão 2015: methodology for atmospheric multi-Doppler lidar experiments, Atmos. Meas. Tech., 10, 3463-3483, https://doi.org/10.5194/amt-103463-2017, 2017.

Vosper, S. B.: Inversion effects on mountain lee waves, Q. J. Roy. Meteorol. Soc., 130, 1723-1748, https://doi.org/10.1256/qj.03.63, 2004.

Walmsley, J. L. and Taylor, P. A.: Boundary-layer flow over topography: Impacts of the Askervein study, Bound.-Lay. Meteorol., 78, 291-320, https://doi.org/10.1007/BF00120939, 1996.

Whiteman, C. D., Lehner, M., Hoch, S. W., Adler, B., Kalthoff, N., and Haiden, T.: Katabatically driven cold air intrusions into a basin atmosphere, J. Appl. Meteorol. Clim., 57, 435-455, https://doi.org/10.1175/JAMC-D-17-0131.1, 2018.

Wilczak, J. M., Stoelinga, M., Berg, L. K., Sharp, J., Draxl, C., McCaffrey, K., Banta, R. M., Bianco, L., Djalalova, I., Lundquist, J. K., Muradyan, P., Choukulkar, A., and Le, A. B.: The Second Wind Forecast Improvement Project (WFIP2): Observational Field Campaign, B. Am. Meteorol. Soc., 100, 1701-1723, https://doi.org/10.1175/BAMS-D-18-0035.1, 2019.

Wyngaard, J. C.: Toward numerical modeling in the "Terra Incognita", J. Atmos. Sci., 61, 1816-1826, https://doi.org/10.1175/15200469(2004)061<1816:TNMITT>2.0.CO;2, 2004. 